\title{
How winds and river discharge affect circulation in a mesotidal estuary, San Francisco
}

Bay, USA

Qianqian $\mathrm{Liu}^{1 *}$, Huijie Xue ${ }^{2}$, Fei Chai ${ }^{2}$, Zhengui Wang ${ }^{5}$, Yi Chao ${ }^{3}$, Shivanesh $\mathrm{Rao}^{4}$, Hongchun Zhang $^{3}$, Yinglong Zhang ${ }^{5}$

[1] Department of Physics and Physical Oceanography, University of North Carolina at

Wilmington, Wilmington, NC 28403, USA

[2] School of Marine Sciences, University of Maine, Orono, ME 04469, USA

[3] Joint Institute for Regional Earth System Science and Engineering, University of California, Los Angeles, CA 90095

[4] Science, Policy \& Strategy, DPIE, NSW Government. Lidcombe, NSW 2141, Australia [5] Virginia Institute of Marine Science, Gloucester Point, VA 23062, USA

This manuscript is a non-peer reviewed preprint submitted to EarthArXiv to ensure rapid and free access to the work. Subsequent versions of the manuscript may have different content.

Please contact the corresponding author if you have any questions or feedback about the manuscript, or if you would like access to the dataset.

${ }^{*}$ Corresponding author: Qianqian Liu, Department of Physics and Physical Oceanography, University of North Carolina at Wilmington, Wilmington, NC 28403; Email address: liuq@uncw.edu 


\begin{abstract}
Previous studies suggest importance of wind forcing on salt intrusion length and salt flux in river-dominated microtidal estuaries (with tidal range $<2 \mathrm{~m}$ ). In this study, we investigate the role of wind forcing on salt intrusion in a mesotidal estuary, San Francisco Bay (SFB), with tidal ranges between $2 \mathrm{~m}$ and $4 \mathrm{~m}$, through an open-source model of high transferability, the Semiimplicit Cross-scale Hydroscience Integrated System Model (SCHISM). Meanwhile, we investigate circulation and salinity variation of San Francisco Bay. The model's performance in hydrodynamics at tidal, spring/neap and seasonal time scales is validated through modelobservation comparisons. Through realistically forced and process-oriented experiments, we demonstrate that spring/neap tides can cause fortnightly variations in salinity and currents by modulating vertical mixing and stratification; and seasonal variability of circulation in North Bay is determined by change of river discharge and modified by winds, while in South Bay it is dominated by wind-driven flows. Furthermore, we revealed the role of wind on X2 (the distance from the Golden Gate Bridge to the 2-PSU isohaline at the bottom). The model results show that $\mathrm{X} 2$ is primarily influenced by river flow and proportional to river flow to the $1 / 4$ power. Meanwhile, wind plays a secondary role in modifying X2 by increasing X2 from 0 to $5 \mathrm{~km}$ during low discharge period, while spring/neap tide modulation on $\mathrm{X} 2$ is negligible but important for salt balance in sub-regions downstream of X2.
\end{abstract}

Keywords: hydrodynamic modelling; estuarine dynamics; mesotidal estuary; seasonal variability; salt intrusion length; wind 


\section{Introduction}

Exchange of salt between coastal ocean and estuaries can have huge ecological impacts, based on the fact that salinity is biologically important by regulating water for organisms [1] (Moyes \& Schulte 2008). Available studies demonstrated that salinity intrusion length and salt transport along an estuarine channel is dominated by tides, freshwater flow and winds [2-6] (Pritchard, 1954; Hunkins, 1981; Monismith et al., 1996, 2002; Wells and Young, 1992). Through an ideal steady-state relationship, available studies found that salinity intrusion has a 1/3 power dependence on river flow [7] (Hansen and Rattray, 1965), and the dependency can change by geometry and the dynamic nature of stratification and salt flux [5,8,9] (Abood, 1974; Bowen, 2000; Monismith et al., 2002).

Numerous studies have investigated role of wind in salinity distributions in estuaries. Among them, the work by Scully et al. [10] (2005) and Chen and Sanford [11] (2009) discussed mechanisms of along-channel winds in altering exchange flow through wind straining and wind mixing. Furthermore, Coogan and Dzwonkowski [12] (2018) found that wind can play a large role in modifying the salt intrusion length in estuaries, comparable to the changes induced by spring-neap cycle in a microtidal (with mean tidal range $<2 \mathrm{~m}$ ) estuary. However, the impact of wind on salt intrusion in mesotidal estuaries (with mean tidal range $2-4 \mathrm{~m}$ ), for example, northern San Francisco Bay (SFB), is open to study.

SFB is the largest estuary along the California coast. As shown in Fig 1, it is composed of three geographically and hydrologically distinct sub-estuaries: the northern reach drained by the freshwater from the Sacramento and San Joaquin rivers (herein after called North Bay), the southern reach from Oakland Bay Bridge to the Coyote Creek (herein after called South Bay), and Central Bay between North and South bays, which contacts directly with the coastal ocean through the Golden Gate. North Bay, comprising the sub-embayments of Suisun and San Pablo bays, is partially mixed and regulated predominantly by the river discharge from the north, while South Bay is a tidally oscillating lagoon-type estuary with rare natural freshwater flows in summer and small runoff from the Coyote Creek in winter [13] (Conomos et al., 1985).

The complex physical processes in SFB are dominated by tides, wind, and hydrological input. Tides in SFB are a mixture of semidiurnal and diurnal constituents $\left(\mathrm{M}_{2}, \mathrm{~S}_{2}, \mathrm{~N}_{2}, \mathrm{~K}_{2}, \mathrm{~K}_{1}, \mathrm{O}_{1}\right.$, $\mathrm{P}_{1}$ and $\mathrm{Q}_{1}$ ) but dominated by semidiurnal type [14,15] (Walters et al., 1985; Peng et al., 2014). They propagate into San Francisco Bay through the Golden Gate and serve as a significant dynamic contributor to mixing processes, and hence to stratification and circulation $[4,14]$ (Walters et al., 1985; Monismith and Fong, 1996). Tides in SFB also experience pronounced spring-neap variations causing significant fluctuations in turbulent mixing, stratification and gravitational circulation as in many other estuaries [4,16-20] (Peters, 1997; Sharples, 2008; Monismith and Fong, 1996; Uncles and Stephens, 1996; Geyer, 1993; Shaha et al., 2010). Wind is another significant contributor to vertical mixing and circulation in SFB, especially during summer and during winter storms, when robust wind drives strong vertical mixing in shallow 
water regions and resuspension of sediments [21] (Smith, 1987). Wind over SFB is orographically driven. In summer, SFB usually experiences prevailing northwesterly winds over the coastal waters and onshore (westerly) winds through the coastal gaps across the bay and delta. The hydrological input to SFB has an evident seasonal variation. According to river discharge data from the U.S. Geological Survey (USGS; http://waterdata.usgs.gov/nwis), freshwater input from the Sacramento, San Joaquin and Napa rivers into the North Bay is largest in wet season from December to April, and decreases significantly in dry season from July to October, with a transition period in May and June. The seasonal variation in hydrological input affects not only SFB's hydrodynamics (Monismith et al., 2002; Martyr-Koller et al., 2017) but also its ecosystem (Dugdale et al., 2012). In South Bay, the hydrological input is much smaller resulting in a relatively longer water-replacement rate than North Bay (Walters et al., 1985).
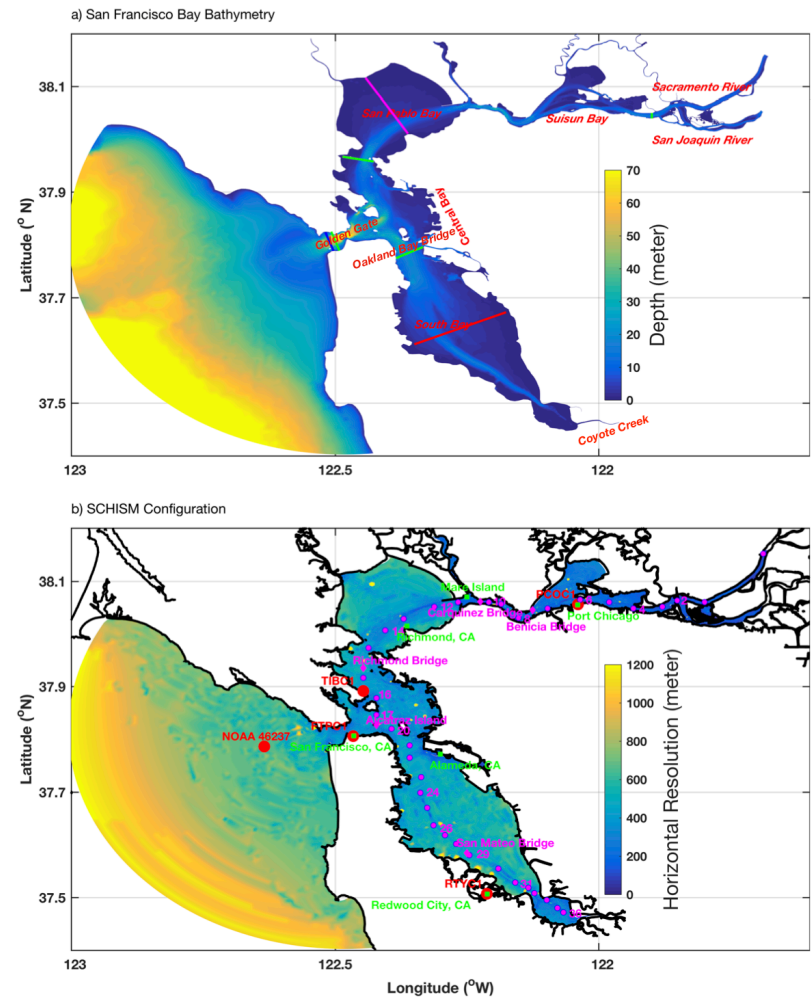

Fig 1. Bathymetry of SFB and model configuration. (a) Bathymetry of SFB. The sections are transects chosen for model results analysis, which are referred in figures below. Green sections are referred in Fig 9; Magenta, blue and red lines sections are referred in Figs 10, 13 and 14. (b) Horizontal resolution of SCHISM model configuration and locations of observations used for model validation, which are referred in figures below. Green dots represent stations for tidal validation, referred in Fig 2; Red dots represent stations for temperature and salinity validation at seasonal scale, referred in Table 3; Magenta dots represent stations for vertical salinity profile validation, referred in Fig 5; Magenta diamonds represent stations for salinity validation over tidal scales, referred in Fig 6. 
Many numerical models have been developed for SFB to study its complex physical processes including estuarine circulation, waves, tides, and salinity distributions (Ford et al., 1990; Wang, 1998; Shi et al., 2011; Chua and Fringer, 2011; Holleman and Stacey, 2014; Peng et al., 2014; Martyr-Koller et al., 2017; Gross et al., 1999; 2005; 2009; MacWilliams et al., 2008; 2015). Among them Gross et al. (1999; 2005; 2009), Monismith et al. (2002), and MacWilliams et al. $(2008 ; 2015)$ investigated the location of the low-salinity zone (LSZ; the area with a daily averaged salinity ranging from 0.5 to 6 PSU) and related X2 (the distance from the Golden Gate to the 2-PSU isohaline at the bottom as defined by Jassby et al. (1995) and Monismith et al. (2002)) to delta outflow through regression analysis, whereas the LSZ and X2 mark the regions where typically the pelagic food web can support juvenile estuarine fishes (Bennett et al., 2002; Kimmerer et al., 2002; MacWilliams et al., 2015). Monismith et al. (2002) found that daily X2 is proportional to river flow to the $1 / 7$ power, and explained the deviation from the classical $1 / 3$ scaling to changes in stratification, while McWilliams et al. (2015) found a stronger scaling with a factor larger than $1 / 5$, which is 0.230 for an equation with variable weight of previous day's $\mathrm{X} 2$, and 0.202 for an equation with a constant weight.

The Delta Modeling Section of the California Department of Water Resources adopted Semi-implicit Cross-scale Hydroscience Integrated System Model (SCHISM) as the de facto three-dimensional model. SCHISM is an open-source, community-supported, modeling system grounded on unstructured grid (Zhang et al., 2008, 2011, 2015, 2016). It employs a highly efficient and accurate semi-implicit finite-element/finite-volume method with EulerianLagrangian algorithm to solve the Navier-Stokes equations; and has been widely applied to bays and estuaries around the world (http://ccrm.vims.edu/schism/schism_pubs.html). Through model-data comparisons of tidal elevation and surface and bottom salinity at different timescales, as well as the vertical structure of salinity, Ateljevich et al. (2014) demonstrated the suitability of the Bay-Delta SCHISM for multi-scale, system-wide SFB modeling. To save computational time for the simulations with a focus on the regions away from the Delta, another SCHSIM configuration covering the SFB region downstream of the Delta, thereafter called Bay version, was developed (Chao et al, 2017a, b). Chao et al. (2017b) validated the Bay version in simulating interannual trends of temperature and salinity in SFB. They eliminated the persistent cold and fresh biases in the model run with modifications to the surface heat flux and river discharge.

In this study, we validate the Bay version of SCHISM model regarding tidal elevation, salinity, tidal currents, and monthly mean circulation in 2011 and 2012 through quantitative analysis and model-observations comparisons. In addition, we demonstrate that this model can be used to systematically investigate the hydrodynamics of SFB at different timescales, including tidal, spring-neap and seasonal, through a hierarchy of process-oriented experiments. We delineate the water exchanges between multiple segments of SFB as well as between SFB and the coastal ocean, complementing the patterns based on historical observations at scattered stations (Walters et al., 1985; Monismith et al., 2002), NOAA stations (https://tidesandcurrents.noaa.gov/stationhome.html?id=9415020), and USGS station (https://ca.water.usgs.gov/projects/baydelta/index.html), and numerical models mainly focused 
on North Bay. Furthermore, using this model we examine X2's response to river flow, wind and spring/neap tides, and discuss salt balance in different subregions of SFB.

\section{Methods}

\subsection{Hydrodynamic Model Configuration}

The SCHISM model configuration used in this study covers the whole SFB and the adjacent coastal area with horizontal resolution ranging from approximately $1 \mathrm{~km}$ in the open ocean portion of the domain to as high as $10 \mathrm{~m}$ in the narrow channels inside the Bay (Fig1b). More grid cells are placed in rivers/creeks to represent small features in ship channels with larger depths that guide the general flow from the rivers and oceans. In the vertical, the model has 23 terrain-following sigma layers with stretching towards the surface. The model uses the Generic Length-scale (GLS) turbulence closure scheme (Umlauf and Burchard, 2003), and the quadratic bottom drag formulation (Blumberg and Mellor, 1987) with a constant bottom drag coefficient $\mathrm{Cd}$ of 0.001. As an implicit model using Eulerian-Lagrangian Method, large time step is encouraged in SCHISM to satisfy the condition of Courant-Friedrich-Lewy $>0.4$ (Zhang and Baptista, 2008). Time step used by our model is $120 \mathrm{~s}$. This study uses the same model configuration (Fig 1b) as in Chao et al. (2017b), but focuses on the circulation and water exchange processes at smaller timescales through process-oriented experiments.

\subsection{Design of Numerical Experiments}

To investigate the dominant dynamics regulating the physical processes at the tidal, springneap and seasonal timescales, a series of process-oriented experiments are carried out (Table 1). The realistic experiments, 'Real2011' and 'Real2012', employ river discharge, tides, atmospheric forcing, and remote forcing from the coastal ocean in 2011 and 2012, respectively. The major rivers (the Sacramento, San Joaquin and Napa Rivers) from the north and Coyote Creek at the lower South Bay are introduced with river flow, salinity, and temperature mainly obtained from the USGS. Flux rate at the mouth of the San Joaquin River is a combination of data from California Data Exchange Center (CDEC; http://cdec.water.ca.gov/) and the USGS data. In addition, discharges from 18 wastewater treatment plants (WWTPs; Liu et al., 2018) in SFB are added in the model with the annual mean flow from Novick and Senn (2014). Even though the WWTPs' discharge is small compared with the large rivers' input in North Bay, it is potentially important for the hydrodynamics in South Bay, especially during dry seasons. The atmospheric forcing is from a 3-km Coupled Ocean Atmosphere Mesoscale Prediction System (COAMPS) regional atmospheric model (Doyle et al., 2009). The open boundary conditions for sea level elevation, temperature, salinity and currents are derived from a 3-km ROMS model (Chao et al., 2017a). 
Table 1. List of process-oriented experiments using the SFB SCHISM.

\begin{tabular}{ccccc}
\hline Run & Tides & River $(\mathbf{m} 3 / \mathbf{s})$ & Wind & $\begin{array}{c}\text { Other Atm. } \\
\text { Forcing }^{*}\end{array}$ \\
\hline Tides & Yes & No & No & No \\
ConstRiv & Yes & Constant & No & No \\
Real2011 & Yes & Yes (2011) & Yes & Yes \\
NoWind & Yes & Yes (2011) & No & No \\
Real2012 & Yes & Yes (2012) & Yes & Yes \\
\hline
\end{tabular}

*The other atmospheric forcing includes air temperature, atmospheric pressure, humidity, precipitation, and solar radiation.

In addition to the realistically forced experiments, we also perform a few other experiments (Table 1). To isolate the tidal effect, in the experiment Tides, the atmospheric forcing and rivers are omitted. To investigate the response of SFB to the wind, in the NoWind experiment local winds are turned off. The experiment ConstRiv is driven by constant river discharge of $500 \mathrm{~m}^{3} / \mathrm{s}$ from the Sacramento, $200 \mathrm{~m}^{3} / \mathrm{s}$ from the San Joaquin, $7 \mathrm{~m}^{3} / \mathrm{s}$ from the Napa Rivers and $2 \mathrm{~m}^{3} / \mathrm{s}$ from the Coyote Creek, which are representative of the annual mean in 2011, and tides through the open boundaries; it is used to examine how the spring-neap variability of tides affects the salinity and estuarine circulation in the bay.

\subsection{Regression model}

Several regression models have been used to estimate X2 as a function of time and flow dependency. Following the form of equation proposed by Monismith et al. (2002), McWilliams et al. (2015) used the following form to estimate the position of X2:

$$
X 2(t)=\alpha(t) X 2(t-1)+(1-\alpha(t)) \beta Q(t)^{\gamma}
$$

Here $t$ is time, $X 2(t)$ is current day's position of $X 2$, and $X 2(t-1)$ is previous day's position of $\mathrm{X} 2, \beta$ and $\gamma$ are scaling coefficients, $Q(t)$ is the current day's net Delta outflow, and $\alpha(t)$ is weight of previous day's $\mathrm{X} 2$, which is bounded between 0 and 1 , and determined by the equation below:

$$
\alpha(t)=\min \left[1, \max \left[0, \alpha_{0}(m Q(t)+b)\right]\right]
$$

Where $m$ and $b$ are parameters used to fit the relationship between a steady flow $\left(Q_{\text {steady }}\right)$ and time scale $(T)$ for the approach to steady state, controlled by the equation below (Monismith et al., 2002):

$$
m Q_{\text {steady }}+b=\frac{T-1}{T}
$$

In this study, we follow the form by McWilliams et al. (2015) to build the relationship between $\mathrm{X} 2$ and $\mathrm{X} 2$ at the previous time and river flow. 


\section{Hydrodynamic Model Evaluation}

To demonstrate the model's performance, we compare the modeled water level, tidal currents, salinity variations in tidal and sub-tidal timescales, and monthly mean circulation in Real2011 and Real2012 with observations through extensive quantitative analysis as shown below.

\subsection{Tides}

We validate the simulated tides by comparing the Sea Surface Height ( $\mathrm{SSH}$ ) at stations of Port Chicago, Mare Island, Richmond, San Francisco, Alameda, and Redwood City spanning across North Bay, Central Bay and South Bay with data obtained from NOAA tides and currents (https://tidesandcurrents.noaa.gov/; see Fig 1b for station locations). Fig 2 shows the hourly observed and modeled SSH with the Root Mean Squared Error (RMSE) for the stations aligned from North to South. In addition, we compared both observed and modeled M2 amplitude and phase at these stations (Table 2) with RMSEs of the amplitude and the phase being $4.7 \mathrm{~cm}$ and $11^{\circ}$, respectively. Despite some discrepancy especially for the station of Port Chicago, the model result matches the observation well regarding tidal elevations.

In SFB, there are 12 major tidal constituents $\left(\mathrm{M}_{2}, \mathrm{~S}_{2}, \mathrm{~N}_{2}, \mathrm{~K}_{2}, \mathrm{~K}_{1}, \mathrm{O}_{1}, \mathrm{P}_{1}, \mathrm{Q}_{1}, \mathrm{MF}, \mathrm{MM}, \mathrm{M}_{4}\right.$, $\mathrm{MS}_{4}$, and $\mathrm{MN}_{4}$ ), with the $\mathrm{M}_{2}$ constituent dominating the tidal energy (Elias et al., 2013). In this study, the tidal velocity is presented through a sequence of snapshots of surface tidal currents over an $\mathrm{M}_{2}$ tidal cycle, and compared with observations from the HF radars (https://tidesandcurrents.noaa.gov/hfradar/Hfscm.jsp?port=SFCA) as shown in Fig 3. Vector correlation coefficient is used to evaluate the relationship between modeled and observed tidal currents. The coefficients for the four snapshots in Fig 3 are $0.88,0.91,0.89$, and 0.56 with the highest correlations occur when the modeled vectors rotate by $2.5^{\circ},-0.9^{\circ},-3.0^{\circ}$ and $10.2^{\circ}$, respectively. The modeled currents are in good agreement with observations. The ebb tide is characterized by an expulsion from Central Bay into coastal ocean through the Golden Gate with velocities in excess of $1 \mathrm{~m} / \mathrm{s}$ (Figs 3a, e). Comparably strong currents coming from North Bay and South Bay merge in Central Bay and turn toward southwest. During the transition from ebb to flood, currents from North Bay are stronger than from South Bay. The flood into SFB (Figs $3 \mathrm{c}, \mathrm{g}$ ) diverts at Central Bay into North and South bays. The flood to ebb transition has a northward flow from South Bay to North Bay. 

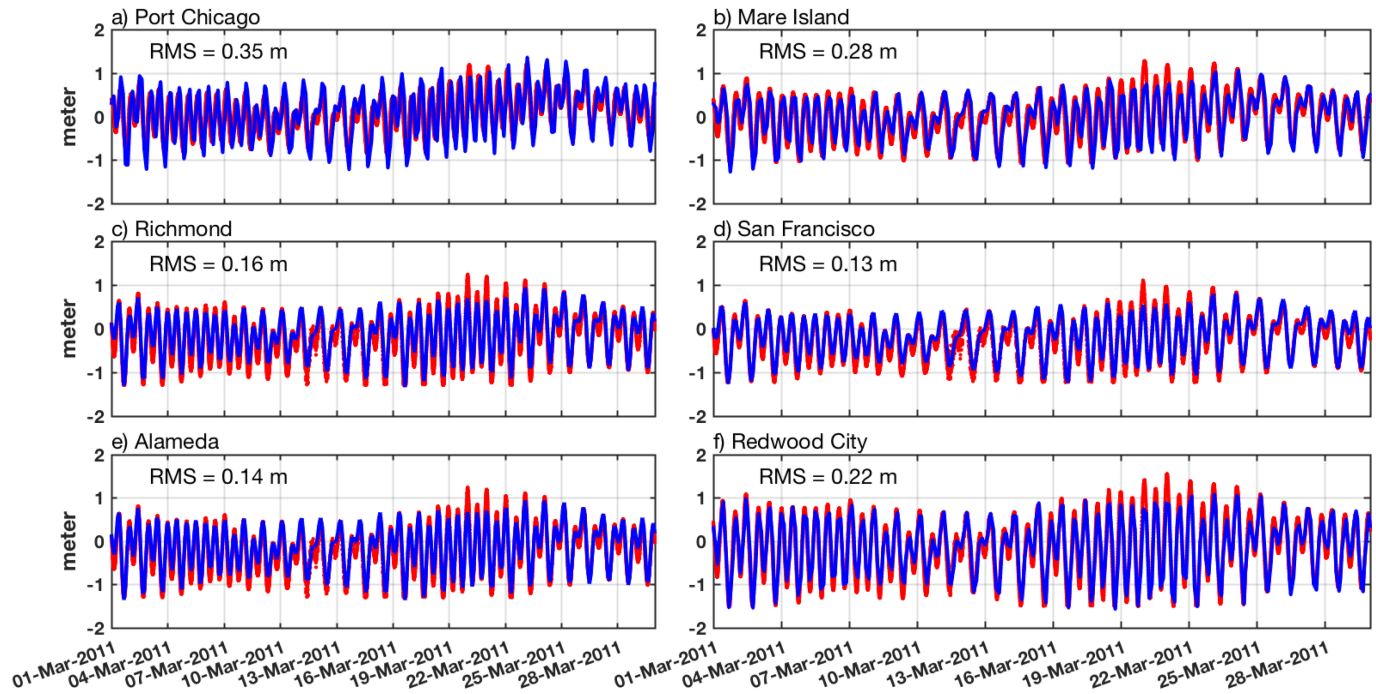

2 f) Redwood City

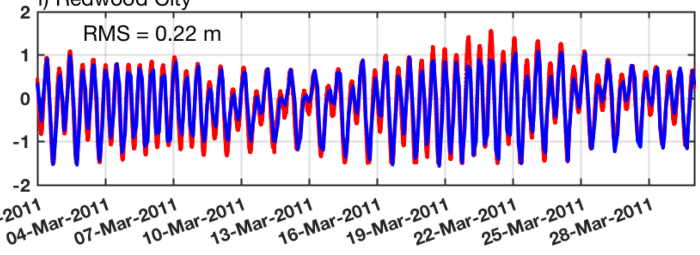

Fig 2. Comparisons of observed (red lines) and modeled (blue lines) tidal elevations at NOAA tides and currents stations of Port Chicago, Mare Island, Richmond, San Francisco, Alameda, and Redwood City (marked as green squares in Fig 1b) spanning North Bay, Central Bay and South Bay. The subtidal signals are removed by simple time averaging.

Table 2. Comparison between observed and modeled amplitude and phase of the $\mathrm{M}_{2}$ tidal elevation at stations in SFB. The locations of the stations are marked in Fig $1 b$.

\begin{tabular}{ccccc}
\hline \multirow{2}{*}{ Station } & \multicolumn{2}{c}{ Amplitude $(\mathrm{m})$} & \multicolumn{2}{c}{ Phase $\left(^{\circ}\right)$} \\
\cline { 2 - 5 } & Observed & Modeled & Observed & Modeled \\
\hline Port Chicago & 0.49 & 0.58 & 50 & 70 \\
Mare Island & 0.58 & 0.62 & 19 & 29 \\
Richmond & 0.64 & 0.59 & 349 & 351 \\
San Francisco & 0.53 & 0.52 & 334 & 338 \\
Alameda & 0.64 & 0.65 & 349 & 351 \\
Redwood City & 0.85 & 0.82 & 2 & 4 \\
\hline
\end{tabular}



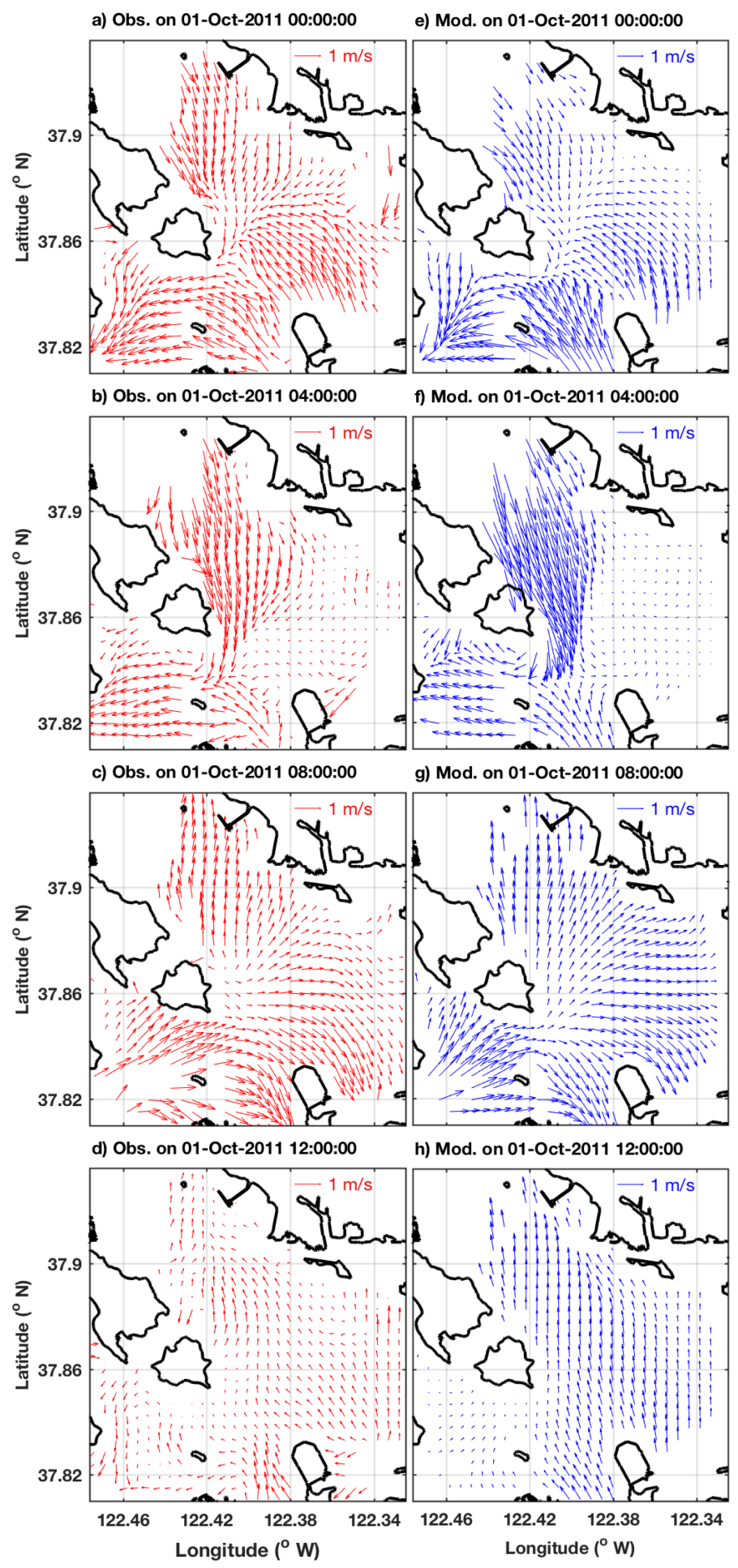

Fig 3. Comparisons of HF radar and modeled currents during one $M 2$ tidal cycle in Central SFB. The observations are from the SFB HF Radar surface currents project started in October 2011. 
Furthermore, we calculated the surface tidal ellipse parameters of the major constituents for both the model output and HF radar data using T_TIDE (Pawlowicz et al., 2002). The comparisons for the top three semidiurnal constituents, $\mathrm{M}_{2}, \mathrm{~S}_{2}$ and $\mathrm{N}_{2}$, and the most important diurnal constituent, $\mathrm{K}_{1}$, are shown in Fig 4. For these four constituents, the ellipses are mainly cyclonic except for around islands and close to the Golden Gate where geometry is complex. For $\mathrm{M}_{2}$, RMSEs for semi-major and semi-minor axes are $6.6 \mathrm{~cm}$ and $4.6 \mathrm{~cm}$, respectively. The model reproduces observations showing the ellipses are close to rectilinear with semi-major axes larger than $1 \mathrm{~m} / \mathrm{s}$ and much smaller semi-minor axes. Between North Bay and South Bay, the ellipses are less rectilinear. The other three tidal constituents show similar patterns, but with much smaller magnitudes. In some regions where ellipses, especially for $\mathrm{M}_{2}$ and $\mathrm{K}_{1}$, are highly rectilinear, for example the lower right corner, the rotations of some tidal ellipses are different between model and observations. Considering the rotary coefficients over such regions are close to 0 , the rotations are highly sensitive to small errors. Therefore, such rotation differences do not hurt the model's fidelity. The normalized RMSEs for the semi-major axis of $\mathrm{M}_{2}, \mathrm{~S}_{2}, \mathrm{~N}_{2}$ and $\mathrm{K}_{1}$ are $2.9 \%, 2.0 \%, 2.4 \%$ and $7.2 \%$, respectively; for the semi-minor axis are $3.8 \%, 7.4 \%, 3.0 \%$ and $5.8 \%$, respectively. The comparisons show that the model overestimates the strength of $\mathrm{K}_{1}$. Overall, the model simulation of tides is very good.

\subsection{Temperature and Salinity}

Chao et al. (2017b) showed that the SCHISM model performs well in simulating the interannual variability of salinity and temperature in SFB. We further validated the model's performance in salinity and temperature at smaller timescales in this section. First, we compare temperature and salinity between model and observations at stations 46237, FTPC1, RTYC1, TIBC1 and PCOC1 (the locations are marked as red dots in Fig 1b). Station 46237 is a buoy operated by the Coastal Data Information Program by UC San Diego since 2007 (http://cdip.ucsd.edu/); FTPC1, RTYC1 and PCOC1 are Water Level Observation Network stations owned and maintained by NOAA's National Ocean Service since 2005 (https://www.ndbc.noaa.gov/); TIBC1 is a coastal marine station owned and maintained by Central and Northern California Ocean Observing System since 2006 (https://www.cencoos.org/). Meteorological and oceanic data are observed at these stations. All stations observe sea surface temperature (SST) for the studied period and station TIBC1 also provides sea surface salinity (SSS).

A quantitative measure of the model skill was proposed and used by Willmott (1981),

$$
\text { Skill }=1-M S E /\left\langle(|m-\langle o\rangle|+|o-\langle o\rangle|)^{2}\right\rangle
$$

where $m$ and $o$ are time series of modeled and observed variables, respectively, and $\langle>$ denotes the mean over time. $M S E$ represents the mean squared error between the model and the observation, i.e., $M S E=\left\langle(m-o)^{2}\right\rangle$. The Skill=1 indicates perfect agreement of the model with observations, whereas $S k i l l=0$ means complete disagreement. This metric was used to evaluate 
the simulations of many estuaries (e.g., Warner et al., 2005; Wilkin et al., 2005; Liu et al., 2009), and it was also used in this study.

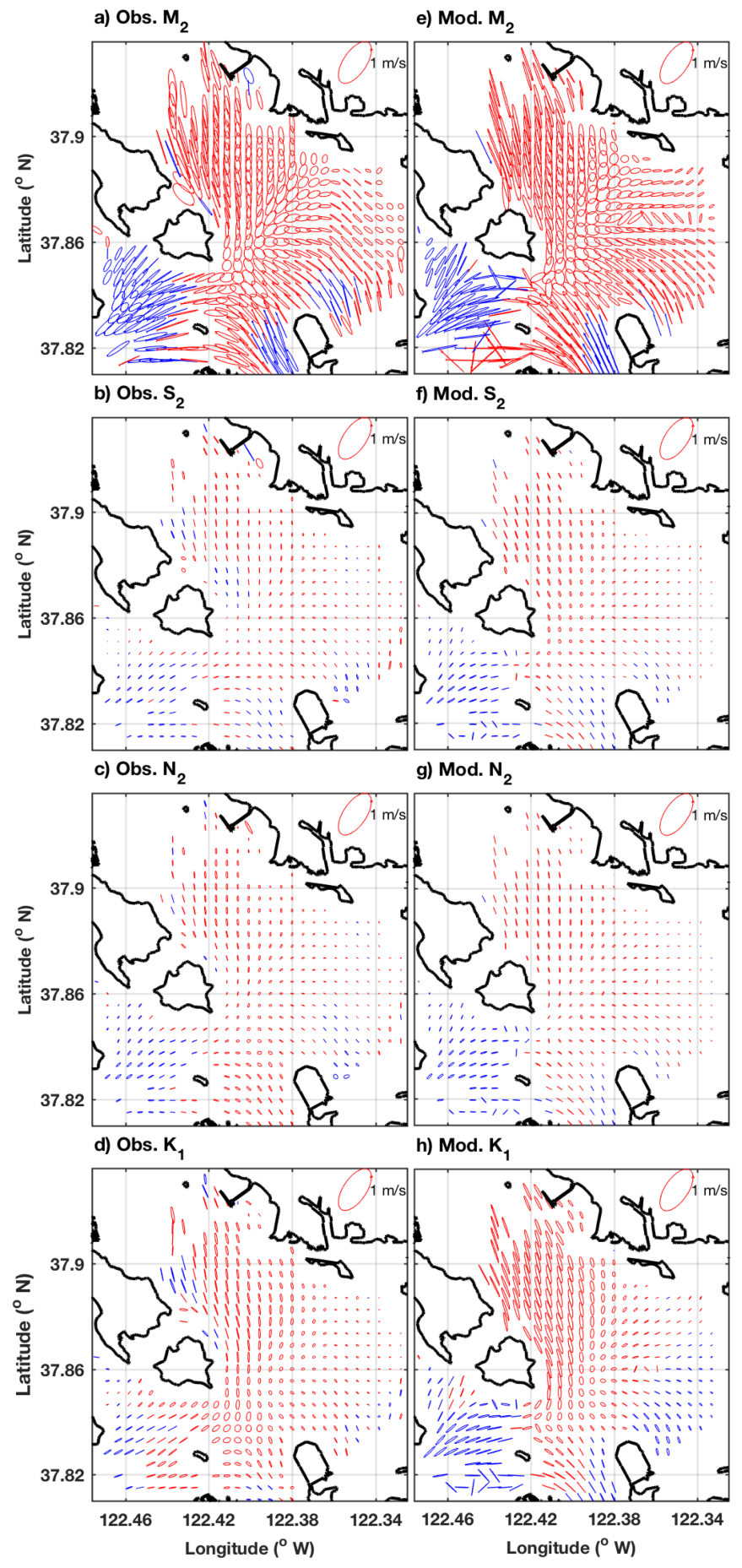

Fig 4. Comparisons of observed (HF radar) and modeled surface tidal ellipses for the constituents of M2, S2, N2 and K1. The red ellipses are cyclonic and blue ellipses are anticyclonic. 
The model skills for sea surface temperature (SST) are shown in Table 2. The SST comparisons have large Skill values with the maximum of 0.93 at the coastal site and TIBC1 and minimum of 0.82 at RTYC1 in South Bay. For the comparison at RTYC1, because the model does not resolve a narrow channel on the eastern shore of South Bay where RTYC1 resides, we choose a model node closest to the observation site. This may explain the relatively larger discrepancy between the model and observations at RTYC1. A comparison of observed and modeled sea surface salinity (SSS) at station TIBC1 further proves the model's fidelity, where the model reproduces well the seasonal variability of the surface salinity with a high Skill of 0.96 (Table 3).

Salinity has been measured by the USGS generally once each month since 1969 at 37 fixed stations along the central deep channel throughout the bay (marked as magenta dots in Fig 1b; http://sfbay.wr.usgs.gov/access/wqdata). Fig 5 shows the observed and modeled salinity transects along the Bay channel for 10 months of 2011. The modeled salinity captures well the seasonal variations of 2 PSU isohaline location: it can reach furthest to Point San Pablo station at the end of March, but retreats to the upstream of Chain Island station in November. The seasonal trend of the high salinity dominated area (defined by 28 PSU by this manuscript) is also well captured by the model.

Table 3. SCHISM model skills for temperature at the stations NOAA 46238 in coastal ocean, FTPC1 at the Golden Gate, TIBC1 (at Tiburon Pier) and PCOC1 in North Bay, TRYC1 in South Bay, and the model skill for salinity at stationTIBC1. The locations of the stations are marked in Fig 1b.

\begin{tabular}{cccccc}
\hline Station & NOAA 46238 & FTPC1 & TIBC1 & PCOC1 & TRYC1 \\
\hline SST Model Skills & 0.93 & 0.89 & 0.93 & 0.92 & 0.82 \\
SSS Model Skills & & & 0.96 & & \\
\hline
\end{tabular}

To assist the skill assessment in salinity stratification, another figure is included in the Supplementary Material to show the temporal variations of modeled surface and bottom salinity in comparison with the observed salinity throughout the water column at single USGS station. (S1 Fig). The model results fit nicely with the observations over most of the studied region with strong seasonal variability in salinity stratification. However, at the end of March, when river discharge peaks, the model underestimates the bottom salinity from USGS stations 12 to 29 (from San Pablo Bay to upper South Bay, also seen in the third panel from the top on the right in Fig 5). This implies that the model underestimates the bottom salt-water intrusion from the coastal ocean during the peak discharge. 

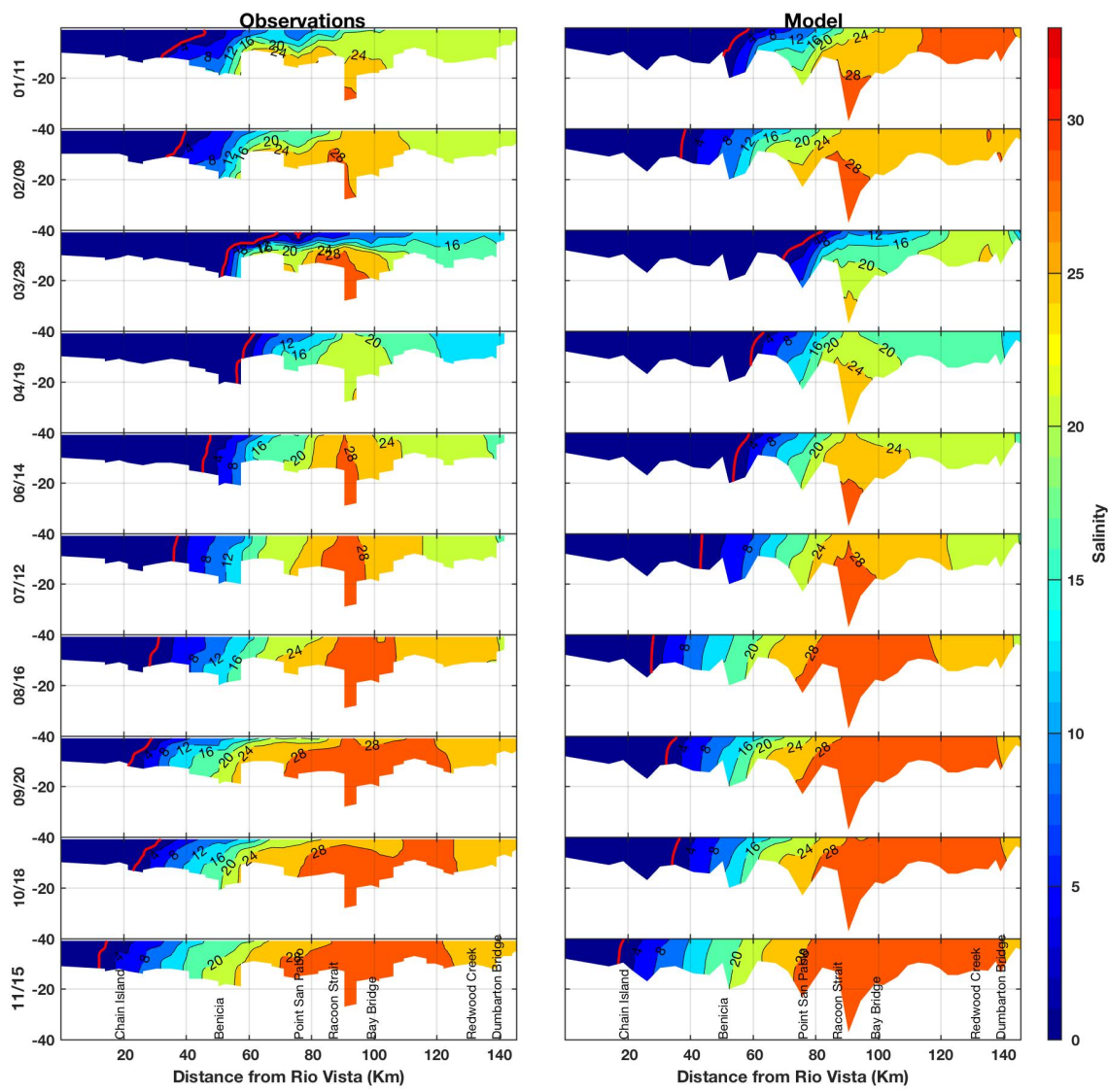

Fig 5. Comparison of observed (left panel) and modeled (right panel) salinity profiles along the USGS stations throughout SFB (marked as magenta dots in Fig 1b) in 2011.

Mooring observations from USGS (https://ca.water.usgs.gov/projects/baydelta/index.html) are used to validate the modeled salinity over tidal scales. Fig 6 shows the comparison between observed and modeled surface salinity at tidal scale (over a half-month period; left panels) and seasonal scale (tidally filtered; right panels) in 2011 at Alcatraz Island, Carquinez Bridge, Richmond Bridge, Benicia Bridge and San Mateo Bridge stations (marked in Fig 1b). The model well captures the salinity variation over tidal cycles for the selected period. Meanwhile, it captures the seasonal trends of salinity with best fit at Benicia Bridge and Alcatraz Island stations with RMSEs of 1.93 PSU and 1.20 PSU. However, similar to the comparisons in S1 Fig, the model underestimates the surface salinity at Carquinez Bridge and Richmond Bridge stations during peak discharge. In South Bay at the San Mateo Bridge station, the model well simulates the seasonal trend of surface salinity, while overestimates the magnitude in March and after September, probably due to the neglect of the discharge from small WWTPs and tributaries in South Bay. 


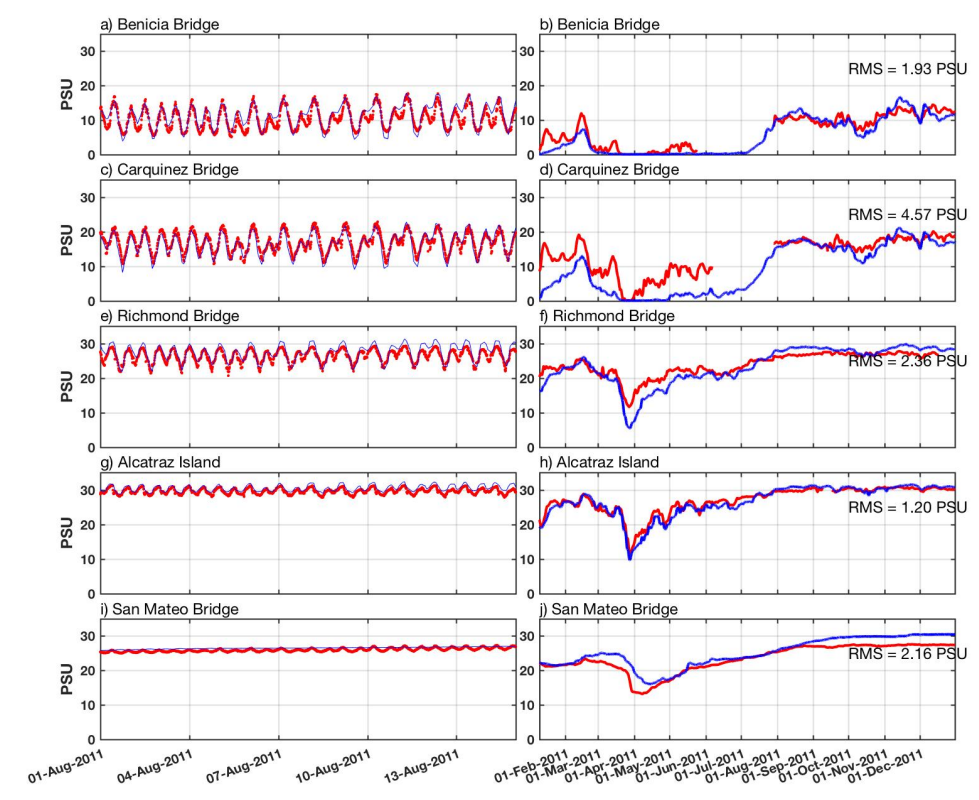

Fig 6. Comparisons of observed (red lines) and modeled (blue lines) surface salinity over tidal and subtidal scales at stations Benicia Bridge, Carquinez Bridge, Richmond Bridge, Alcatraz Island and San Mateo Bridge stations (with the locations marked as magenta diamonds in Fig 1b). The observed salinity is obtained from USGS (https:/ca.water.usgs.gov /projects/baydelta/index.html).

Overall, the salinity comparisons show that our model underestimates intrusion from the coastal ocean during the peak discharge (Fig 5), which has been a problem in some models previously applied to SFB (Marty-Koller et al., 2017). In addition, the mixing processes in the narrow-curved channel around USGS stations 12 and 14 are overestimated with lower surface salinity at the Carquinez Bridge station (a station within the narrow channel; Fig 6) and higher bottom salinity (S2 Fig) than observations. This requires the improvement of the model's performance in lateral mixing, which are proven to be important for estuarine flows with curvature (Nidzieko et al., 2009). With SCHISM's capability, we can potentially improve this by a) increasing horizontal resolution around the curvature, b) applying the new vertical coordinate option (LSC2; Zhang et al., 2015), which improves mixing in regions where steep slope exists, and 3) using a higher-order transport scheme implemented in SCHISM (Zhang et al., 2016).

\subsection{Monthly Mean Surface Currents}

To verify the modeled currents on subtidal timescale we compared monthly mean surface currents between the model result and HF radar data in December 2011, March 2012, June 2012, and September 2012 (Fig 7). The total vector correlation between the monthly mean modeled and observed circulation over the four months is 0.64 with the largest correlation occurs when the modeled circulation rotates $6^{\circ}$. For each time stamp, the vector correlation is $0.67,0.66,0.46$, 0.65 with modeled circulation rotation of $11^{\circ}, 1^{\circ}, 15^{\circ}$ and $9^{\circ}$, respectively. It shows that modeled 
circulation pattern is in a good agreement with observations. Generally, the circulation in Central Bay was characterized by a flow, $\sim 20 \mathrm{~cm} / \mathrm{s}$, from North Bay, which was stronger along the western shore and weaker along the eastern shore. The water exchange between Central Bay and South Bay was dominated by a flow from Central Bay to South Bay along the eastern shore, and a flow out of South Bay along the western shore. Both the modeled and the observed circulation pattern show strong seasonal variability. The flow along the eastern shore between North Bay and Central Bay moved southward in December 2011, and reversed to northward in June 2012 and September 2012. Simultaneously, currents in the middle of Central Bay turned from westward to eastward.

\section{Results}

The comparisons presented in Section 3 above and those by Chao et al. (2017b) prove that this model captures the major tidal, subtidal and seasonal dynamics in SFB, and therefore, is suitable for studying SFB's hydrodynamic processes at the related timescales. Here we use the model to investigate the variations of circulation and water exchange processes in SFB at different timescales through process-oriented experiments.

\subsection{Tide-dominated processes}

Tidal residual currents are generated when strong oscillatory tidal currents interact with the bottom topography or coastline (Loder, 1980; Liu et al., 2016). Even though different constituents have different tidal periods, which cannot be completely removed by simple averaging method, the tidal residual circulation referred in this study is the long-term mean flow by averaging the currents over one year simulation from the experiment Tides that excludes river and wind forcing. Fig 8 shows the depth-averaged tidal residual currents in SFB. The complex geomorphology and topography of SFB give rise to a rather complex circulation pattern. Tidal residual currents in South Bay are characterized by two major circulations in opposite directions: a cyclonic one at the lower South Bay and the anti-cyclonic one located north of it, which agrees well with the observed residual flow directions by Waters et al. (1985), who found a northwestward current (the direction is highlighted by the red arrow in Fig 8) along the western shore in the widest part of South Bay, and an eastward flow (magenta arrows) at the upper end of San Bruno Shoal. At Bay Bridge in Oakland, northward current along the western shore and southward current along the eastern shore were observed (green arrows), which formed an anticyclonic circulation around the Treasure Island. In San Pablo Bay, residual currents are dominated by an anti-cyclonic circulation. In Central Bay, one can identify complex recirculation/eddies arising from tides interacting with the topography.

The combining effects of tides and river inflow are discussed using the experiment ConstRiv. Without signals from seasonal river discharge, this experiment ConstRiv clearly shows the estuarine circulation and tidal asymmetry (S3 Fig). As a main factor controlling the estuarine 
circulation, spring-neap changes of tidal currents result in fortnightly modulation of salinity stratification (represented as salinity difference between the bottom and surface waters, $\Delta \mathrm{S}$ ) and gravitational circulation (Simpson and Souza, 1995). S2 Fig shows that the observed salinity stratification in SFB fluctuates at fortnightly period in addition to semi-diurnal tidal $\left(\mathrm{M}_{2}\right)$ and diurnal periods.

The spring-neap fortnightly signal stands out in the experiment ConstRiv. Fig 9b shows the stratification from days 100 to 130 (corresponding to the peak discharge period) along the USGS stations shown in Fig 1b. Spatially, the maximum stratification occurs between USGS 10 and USGS 22. Since our model underestimates the saltwater intrusion north of Richmond, the stratification in the real ocean can be larger. At the stratified stations (USGS 10-23), the maximum stratification occurs during neap tide, and minimum around spring tide (Fig 9b).

Variations of the salt flux across multiple cross-sections in SFB (green lines in Fig 1a) during the spring-neap cycle are calculated and shown in Fig 9c. The salt flux during neap tide is larger than during spring tide, which is generated by the change of estuarine circulation due to change of vertical mixing. Therefore, salt flux can represent the strength of gravitational circulation.

Fig 10 shows the vertical structures of estuarine circulation across North Bay, the Gold Gate Strait and South Bay through the sections marked as magenta, blue and red lines in Fig 1a, respectively. Salinity stratification in North Bay and at the Golden Gate is weaker during spring tides (at day 107) than neap tides (at day 115) due to the stronger vertical turbulent mixing during spring tides. For the same reason, at the Golden Gate, the isohalines are steeper during spring than neap. Meanwhile, width of the seaward current (negative values) is relatively narrower during spring tides. For the section in South Bay, because it is also affected by the Coyote Creek, water is fresher along the eastern shore than western shore. Consistent with the sections in North Bay and across the Golden Gate Strait, the width of the seaward current (positive values) is narrower during spring than during neap. 

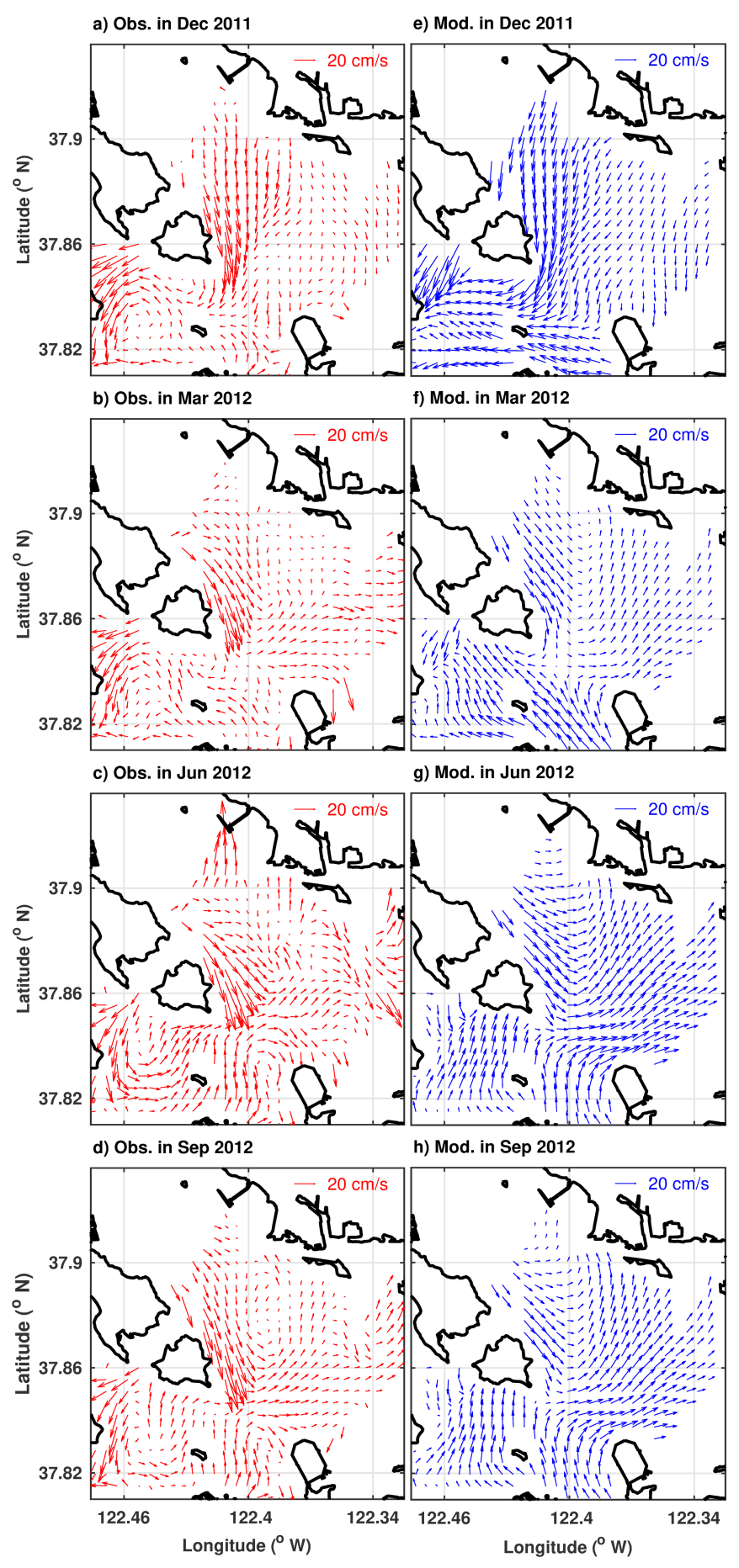

Fig 7. Comparisons of observed (HF radar) and modeled monthly mean circulation in December 2011, March 2012, June 2012 and September 2012. 


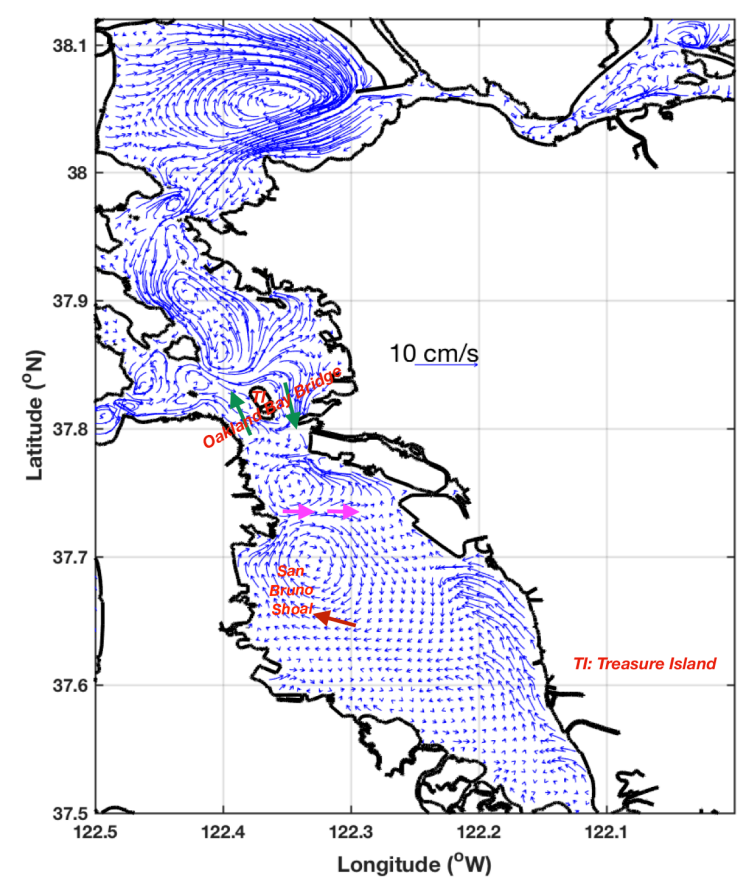

Fig 8. Depth-averaged tidal residual currents from the experiment Tides. The colored arrows highlight the directions discussed in Section 4.1.

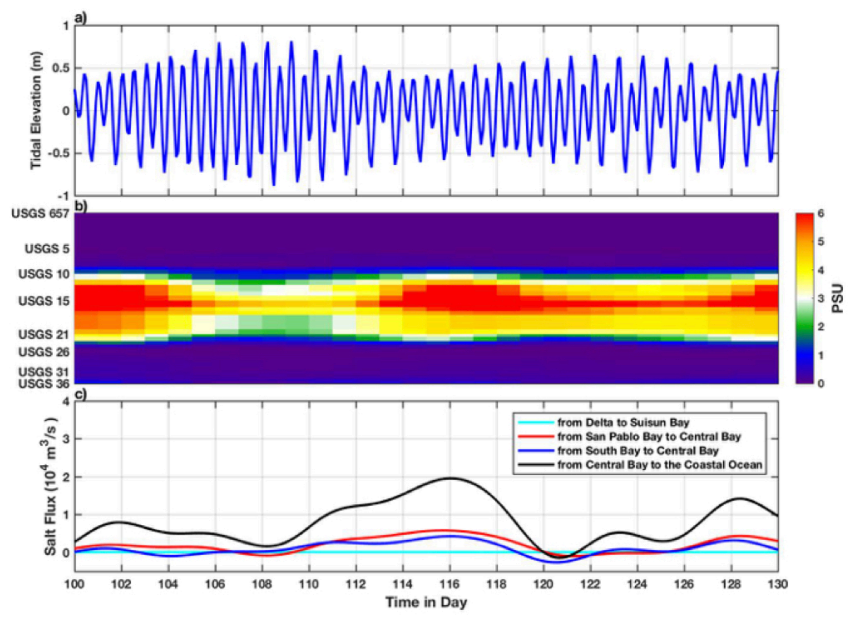

Fig 9. Time series of hourly-averaged a) tidal elevation, b) salinity stratification (bottom salinity - surface salinity) along the USGS stations in Fig 1b, and c) salt flux for the experiment ConstRiv during spring-neap cycles. 

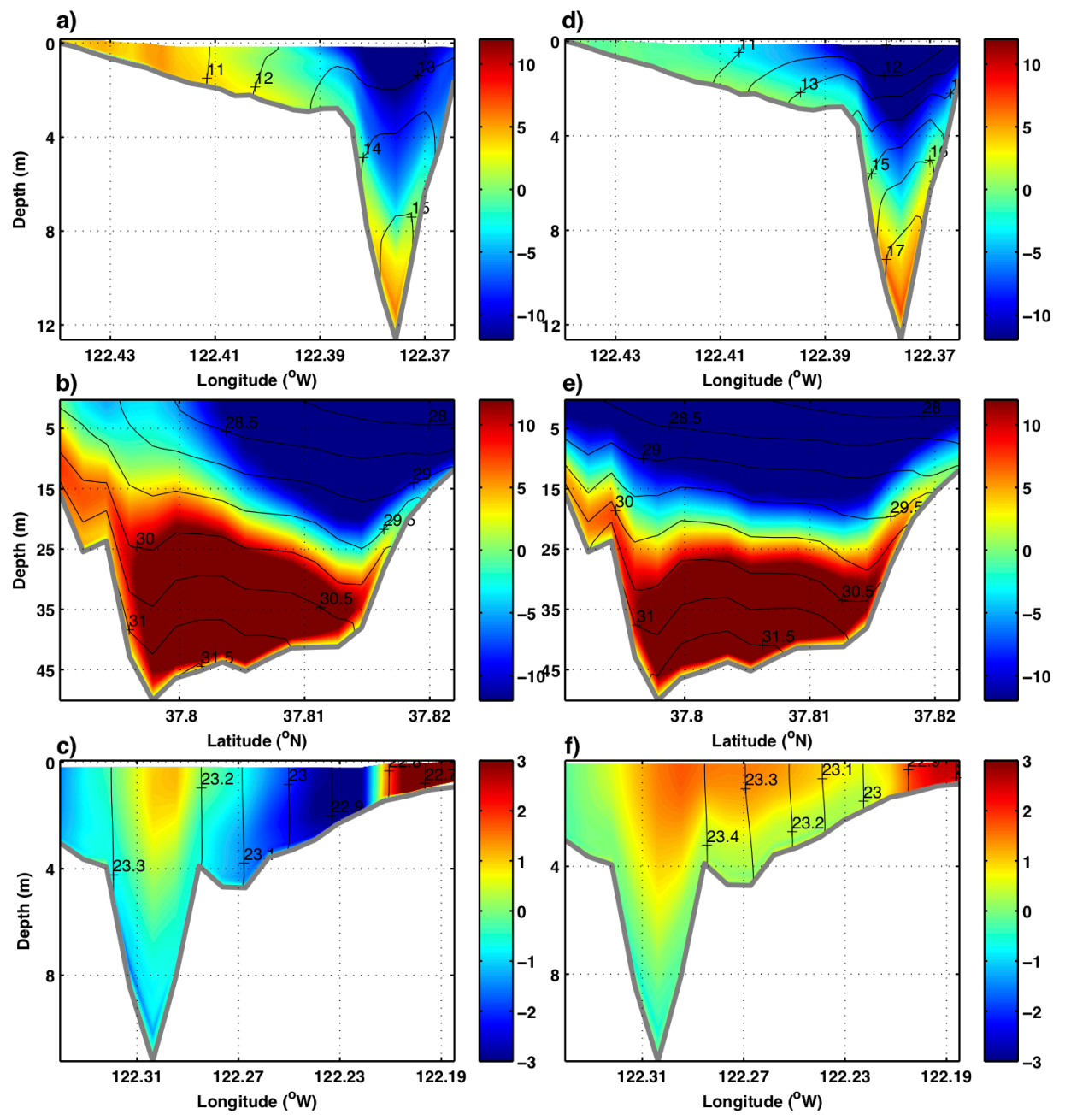

Fig 10. Daily-averaged estuarine circulation for the experiment ConstRiv during spring (at day 107; left panels) and neap tides (at day 115; right panels) in a) and d) North Bay, b) and e) the Golden Gate Strait, and c) and f) South Bay. The sections are marked as magenta, blue and red lines in Fig la, respectively. Colors represent velocities (in $\mathrm{cm} / \mathrm{s}$ ) across the sections. For all sections, positive currents moving toward the SacramentoSan Joaquin delta, and negative currents moving away from the delta. Black contours represent salinity.

\subsection{Seasonal variability of SFB}

\subsubsection{Seasonal variability of the salinity and circulation}

We have shown that the change of river discharge in Real2011 causes the seasonal variability of surface salinity and salinity stratification in North Bay, with the strongest stratification in April but much weaker from August to December (Fig 5 and S1 Fig). In South Bay, tidal currents 
dominate over buoyancy gradient, except in April when the freshwater intrusion from North Bay increases. Below we will show the seasonal variability of circulation.

The monthly-mean, depth-averaged circulation of March, June, September and December from the experiment Real2011 is shown to represent spring, summer, fall and winter in SFB (Fig 11). In North Bay the circulation pattern changes less than magnitude from season to season, except for area along the northern shore of San Pablo Bay, where current moves eastward in March, June and September, but moves westward in December. Similar to the tidal residual circulation, North Bay is featured with an anti-cyclonic gyre in San Pablo Bay. However, from San Pablo Bay to Central Bay, it is dominated by a seaward (southward) flow, in contrast to the tidal residual currents (Fig 8) featured with a landward (up-estuary) current along the eastern shore. The landward flow is significantly weakened or even suppressed as a result of the strong freshwater discharge from the Sacramento and San Joaquin rivers. In March, when river discharge peaks, the landward current disappears; in June, September and December, a cyclonic gyre is formed instead. Meanwhile, strength of the seaward current and the anti-cyclonic gyre in San Pablo Bay exhibits strong seasonal variability with largest magnitude in March (wet season) and smallest in September (dry season).

In contrast to the weak seasonal change in North Bay, the circulation pattern changes dramatically in South Bay. In March, the moving gyres seen in the tidal residual still exists. In June, when prevailing westerly winds dominate, the tidal residual circulation pattern in lower South Bay disappears and is replaced by a gyre opposite to the tidal-residual circulation pattern as seen in Fig 8. In September and December, when westerly wind still dominates over other winds, a southward current along the eastern shore occurs with a northward current along the western shore. Therefore, in South Bay where natural discharge input is weak, wind plays a major role in the change of seasonal circulation pattern. This can be proved by comparing the modeled circulation pattern in Real2011 with in NoWind.

\subsubsection{Seasonal variability of circulation due to winds}

To investigate the response of SFB to wind by comparing with the baseline experiment Real2011, in the NoWind experiment local winds are turned off. Fig 12 shows the modeled circulation pattern with the difference between Real2011 and NoWind experiment shown in S4 Fig. In San Pablo Bay the circulation pattern in NoWind experiment remains the same year around, and similar to that in March, June and September from the experiment Real2011. However, compared with Real2011, magnitude of the eastward current along the northern shore of San Pablo Bay becomes much weaker especially in March and reverses in December. Thus, for North Bay wind mostly affects the shallow shoal regions by dragging the surface waters in the direction of wind. 

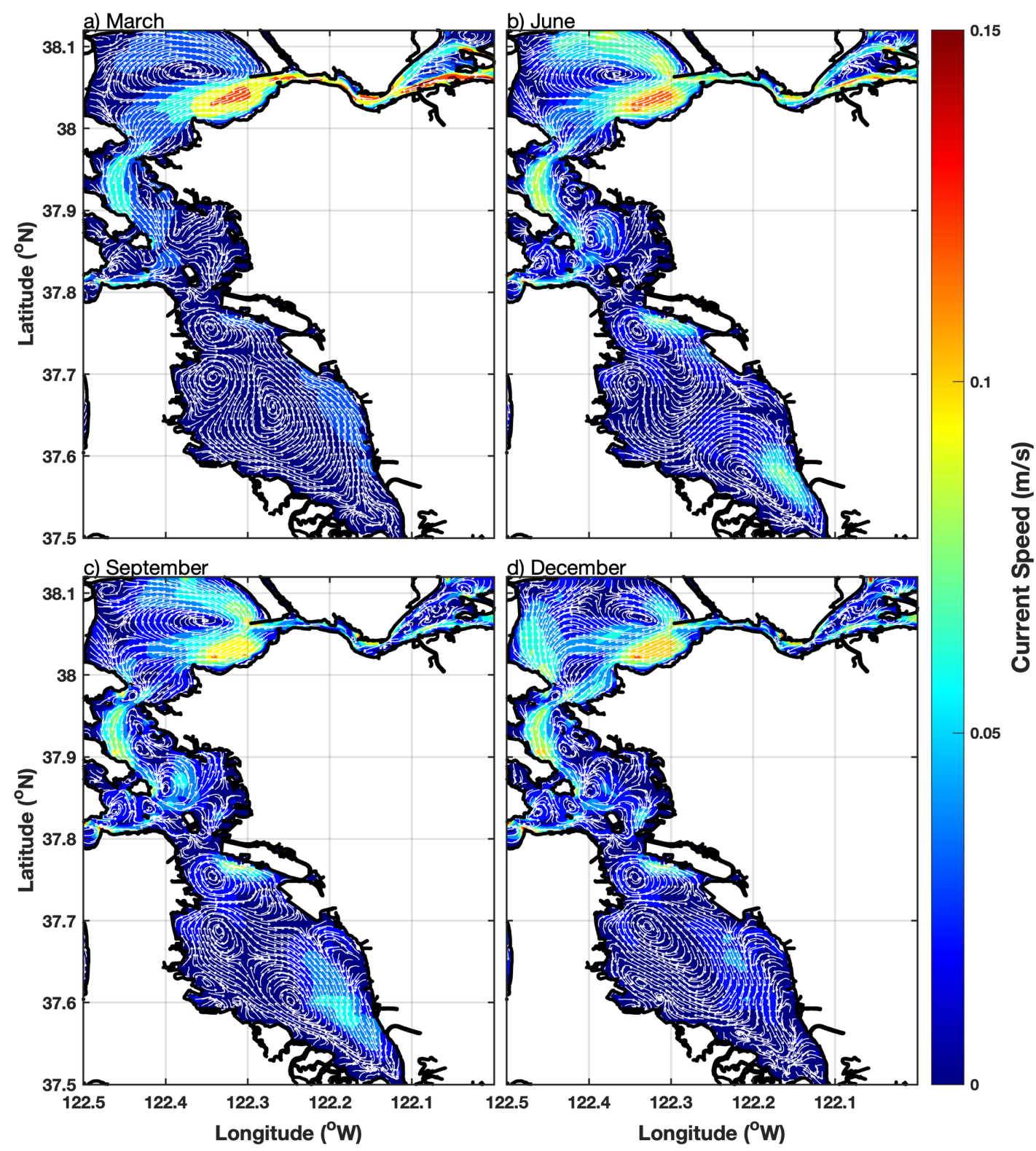

Fig 11. Monthly mean depth-averaged circulation in SFB in March, June, September and December in experiment Real2011. Colors represent speed and arrows represent direction of velocity. 


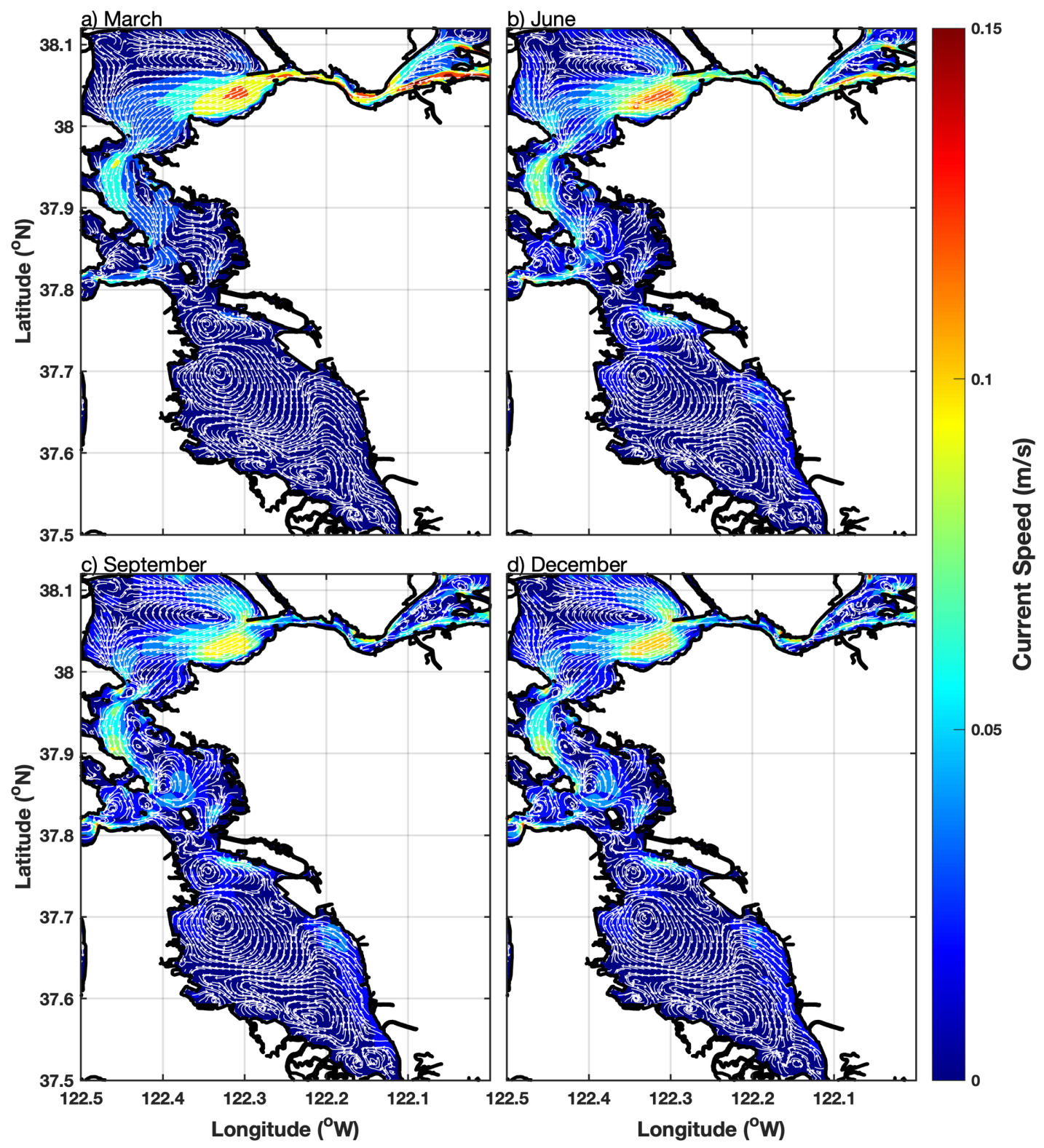

Fig 12. Monthly mean depth-averaged circulation in SFB in a) March, b) June, c) September and d) December in the experiment NoWind.

In South Bay, the NoWind experiment also shows a persistent year-round pattern, which is the tidal-residual circulation pattern (Fig 12) and significantly different from the pattern in the experiment Real2011 (S4 Fig) especially at the lower South Bay. Therefore, it is the wind that reverses the tidal residual circulation pattern in March to the pattern in June, i.e., to anti-cyclonic (cyclonic) in the lower (upper) South Bay. This is in agreement with the study by Walters et al. (1985) who found a counter effect between wind-driven circulation and tidally driven residual circulation in South Bay. 
In the NoWind experiment, we keep all the other atmospheric forcing unchanged (Table 2). The fact of the South Bay showing a persistent year-round circulation pattern in NoWind demonstrates that the other atmospheric forcing does not have a significant effect on the circulation.

\subsubsection{Seasonal variability of vertical structure}

Fig 13 shows the monthly mean vertical structures of velocity and salinity along the crosssections in San Pablo Bay, Golden Gate Strait and South Bay (marked as the magenta, blue and red lines in Fig 1a respectively) in March and September for the experiment Real2011.
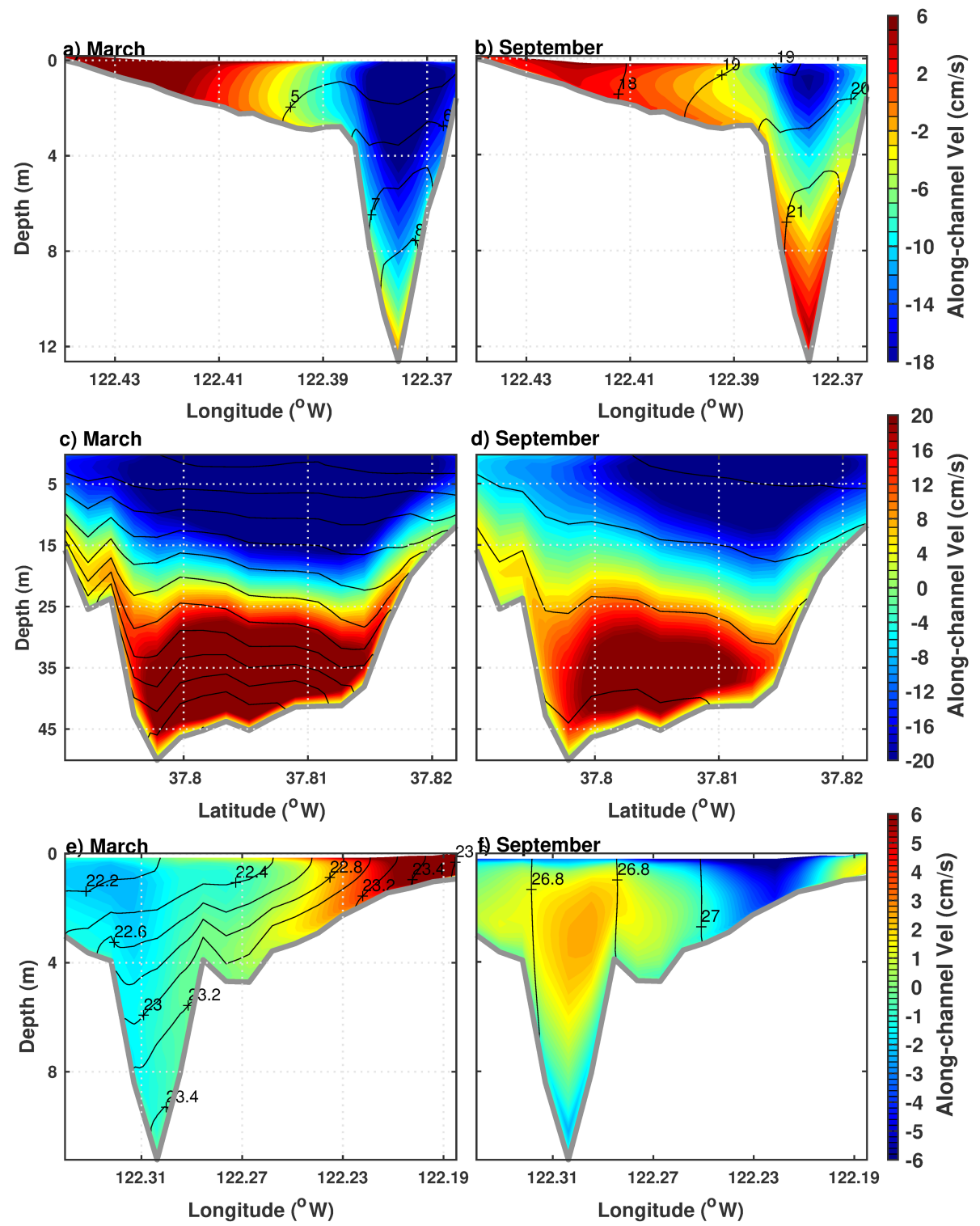

Fig 13. Monthly mean distributions of salinity and velocity from the experiment Real2011 in March (left panels) and September (right panels) across the transects in North Bay, the Golden Gate Strait and South Bay (marked as magenta, blue and red lines respectively in Fig 1a). The top panels are for North Bay; the middle panels are for the Golden Gate Strait, and the bottom panels are for South Bay. Positive velocity represents current moving northeastward 
(landward) in North Bay, eastward (landward) at the Golden Gate, and northwestward (seaward) in South Bay.

The water column in San Pablo Bay experiences strong seasonal variability in salinity with fresher water in March ( $<5$ PSU at the surface) and saltier water in September (between 18 and 20 PSU at the surface). Meanwhile, currents along the transect experience noticeable seasonal variations, especially for the deep channel along the south shore. From March to September, the surface seaward current becomes weaker and thinner, while the bottom landward current becomes stronger and thicker.

At the Golden Gate transect, the monthly mean velocity and salinity (Figs 13c, d) depict a typical estuarine circulation with fresher surface water moving seaward leaning to the northern shore and saltier bottom water moving toward SFB leaning to the southern shore. In March, due to the stronger freshwater discharge, the water exchange through the Golden Gate Strait is more vigorous with stronger salinity stratification (bottom-to-surface salinity difference of 5.5 PSU) than in September (salinity difference of 1.5 PSU).

In addition to the seasonal effect of wind, 2011 was a wet year with abnormally high river inflow, and the influence of freshwater discharge from North Bay can be seen at a section in the widest part of South Bay (Fig 13e and f). In March, the buoyancy input enters South Bay through the southward currents along the western shore. The northward current along the eastern shore brings saline water to Central Bay. The pattern extends throughout the water column. In September, the freshwater intrusion from Central Bay is weak (Fig 5). The vertical current structure features with northward current along the western shore and southward current along the eastern shore (Fig 13f) opposite to those in March. Furthermore, the vertical pattern is consistent with the observations by Walters et al. (1985) who found the three-layer flows in the deeper part of South Bay, i.e., landward near the surface and bottom and seaward in the mid water column. The three-layer structure is driven by a combination of west-northwesterly wind and density differences between Central Bay and South Bay. When the density of Central Bay is larger than South Bay, the density-driven exchange causes salty water intrusion to South Bay near the bottom and outflow above it. These seasonal variations in the circulation pattern play an important role in the sediment transport, and can provide the study of sediment transport with a good reference (Shellenbarger, 2013).

Wind effect on salinity and velocity distributions can be analyzed by comparing NoWind (Fig 14) and Real2011 experiments. For San Pablo Bay, the presence of wind in Real2011 decreases stratification with higher salinity (especially in March) than in NoWind (Figs 14a, b). That is because the studied region is dominated by up-estuary wind (Fig 15c). According to Chen and Sanford (2009), up-estuary wind tends to reduce stratification through both wind straining and wind mixing. Similar situation occurs for the section in the Golden Gate Strait. In contrast, South Bay undergoes much stronger changes in pattern. The three-layer flows seen in experiment Real2011 (Figs 13e, f) disappear in the NoWind (Figs 14e, f), while the density-driven exchange 
becomes more prominent. The density-driven exchange is featured with high salinity water moving seaward near the bottom and the fresher water moving seaward near the surface in March, and salty water moving landward near the bottom with an outflow above in September.
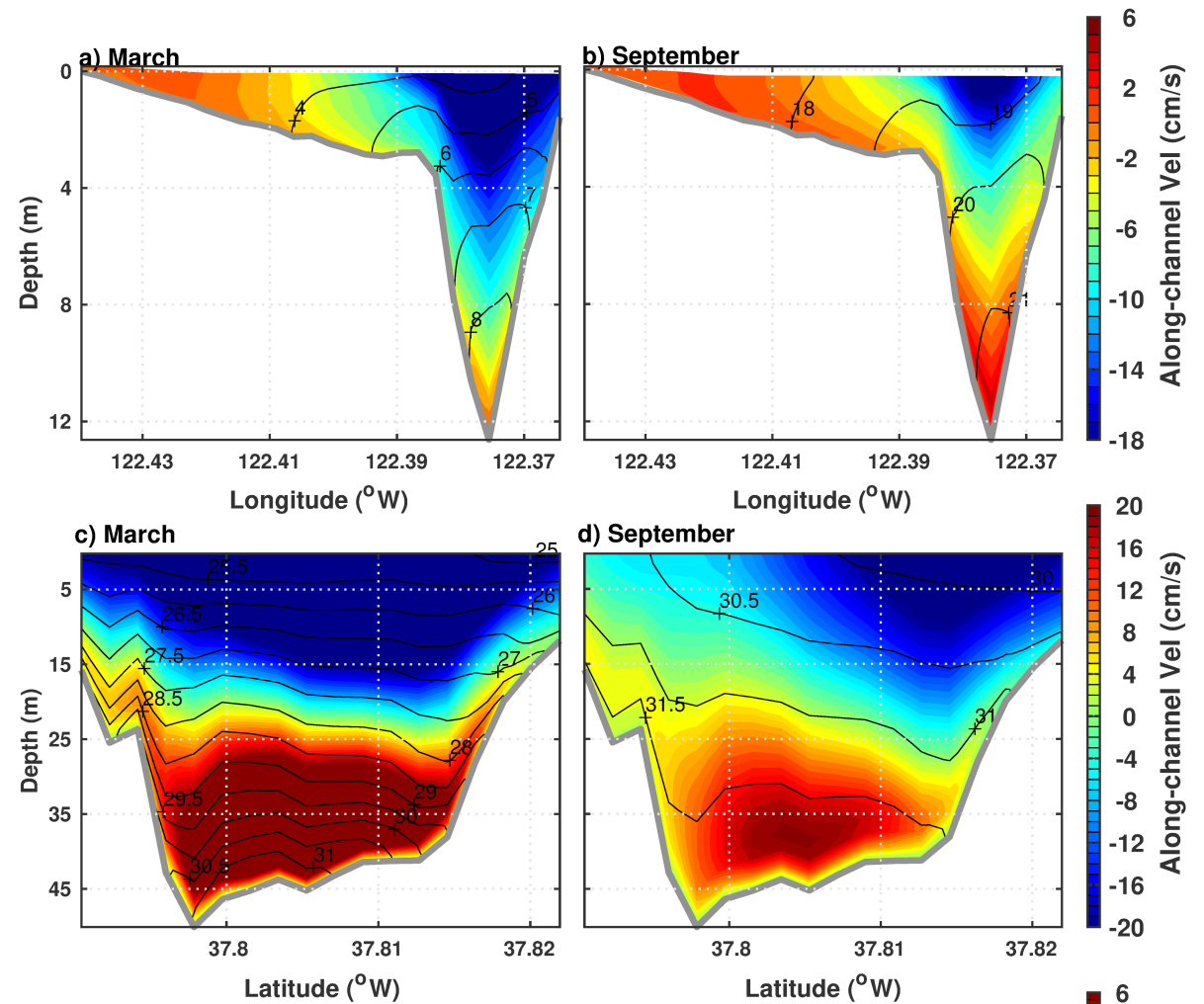

d) September
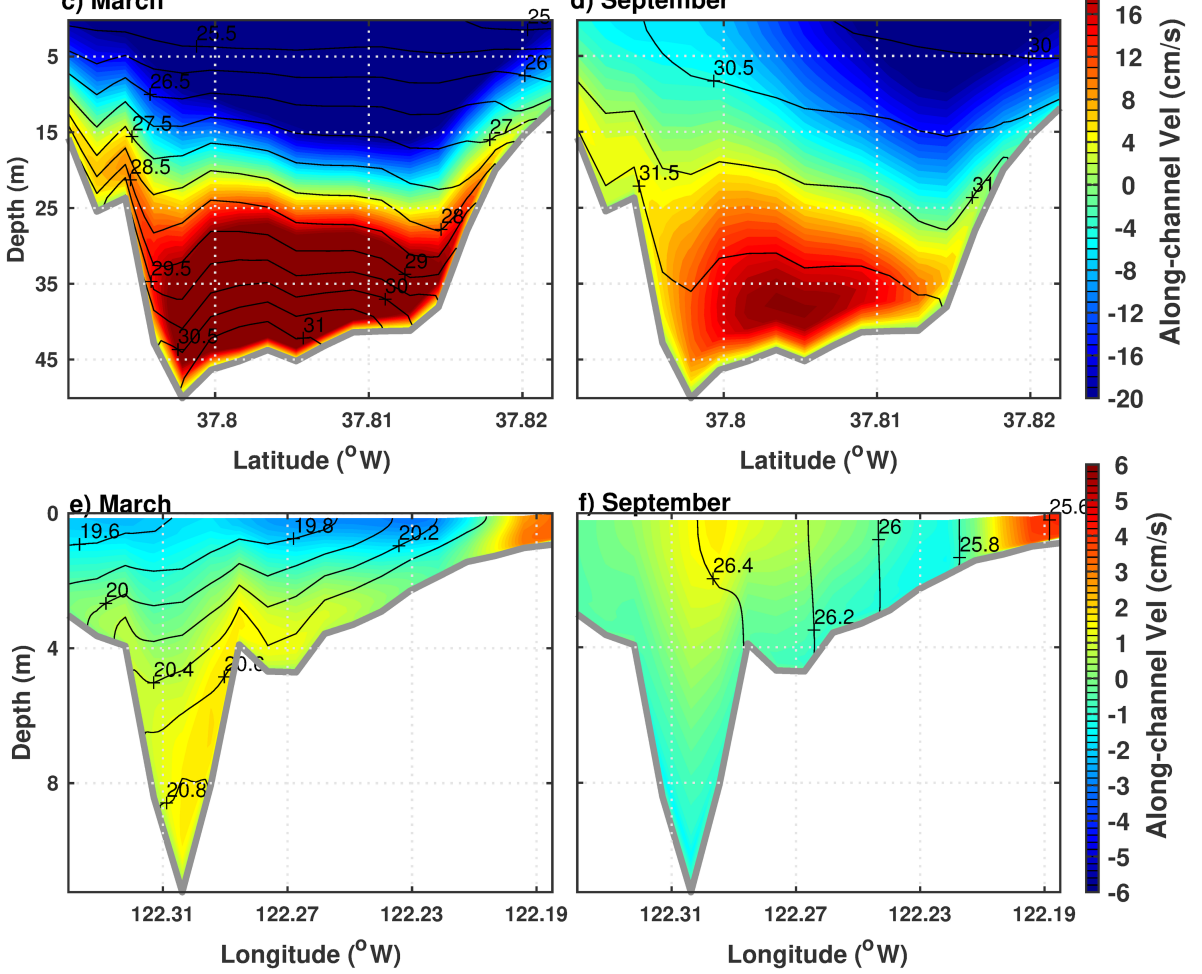

Fig 14. Monthly mean distributions of salinity and along-channel velocity along the transects in North Bay, the Golden Gate Strait and South Bay (marked as magenta, blue and red lines respectively in Fig 1a) in March (left panels) and September (right panels) from the experiment NoWind. 


\section{Discussion}

\subsection{Time and flow dependency of X2}

A transect along the axis of Northern SFB is used to calculate X2 with station USGS 15 around X2 of $25 \mathrm{~km}$, USGS 10 around $50 \mathrm{~km}$, USGS 6 around $70 \mathrm{~km}$. To calculate X2, we locate the 2 PSU bottom salinity, and calculate distance between the Golden Gate bridge and the 2 PSU near bottom salinity. X2 values in every 2 hours were estimated from the model outputs. Since the regression equations by Monsimith et al. (2002) and MacWilliams et al. (2015) are for daily X2 position, we remove signals with periods smaller than 1 day through a low-pass filter. Fig 15a shows X2 from different experiments. The only difference in forcing between ConstRiv to NoWind experiments is river discharge with a constant discharge in ConstRiv and seasonally varying discharge in NoWind. The change in X2 from ConstRiv to NoWind demonstrates that the strong temporal variations in $\mathrm{X} 2$ in NoWind is dominated by river discharge.
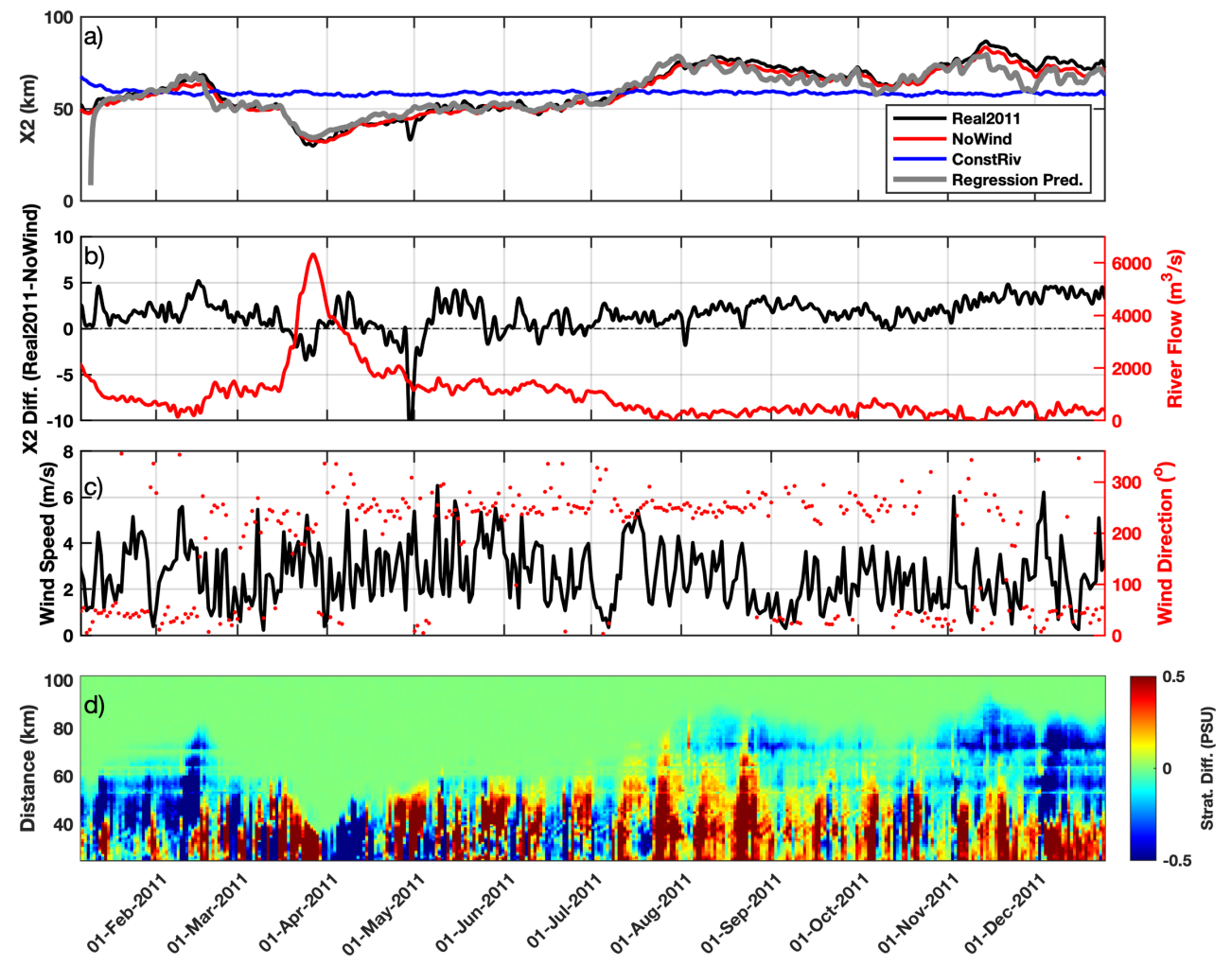

Fig 15. a) X2 from process-oriented experiments Real2011, NoWind and ConstRiv, and regression prediction following McWilliams et al. (2015); b) X2 difference between Real2011 and NoWind (Real2011-NoWind; black line) and total river flow from the Sacramento-San Joaquin Rivers (red line); c) Daily averaged wind in Suisun Bay. The unit for wind direction is degree from true North, increasing clockwise, with North as 0 (zero); d) Difference in salinity stratification (bottom salinity - surface salinity) between Real2011 and NoWind (Real2011-NoWind). Y-axis is the distance from the Golden Gate bridge. 
Our idealized steady flow experiments reproduced time scales that are consistent with MacWilliams et al. (2015). Therefore, we apply the parameters used by MacWilliams et al. (2015) with $m=-0.0001116$ and $b=0.9773$, and then develop the relationship between estuary outflow and X2 from Real2011 based on Eq. (1). The resulting parameters are $\alpha_{0}=$ $1.025, \beta=285$ and $\gamma=-0.242$. The RMSE between modeled X2 in NoWind and the predicted X2 by (1) is $3.4 \mathrm{~km}$. Therefore, $\mathrm{X} 2$ is proportional to river flow to the $1 / 4$ power, which is close to result of 0.23 in MacWilliams et al. (2015).

\subsection{Wind and spring/neap tide effects on $\mathrm{X} 2$ and salt flux}

From Real2011 to NoWind, wind effects are removed. Therefore, the difference in X2 between these two experiments is due to wind. From NoWind to Real2011, X2 increases by an extent ranging from 0 to $5 \mathrm{~km}$, especially during low discharge period (Fig 15b. The salinity intrusion is closely related to stratification. Wind around Suisun Bay is dominated by up-estuary direction (around $270^{\circ}$ in Fig 15c). Stratification difference between Real2011 and NoWind experiments (Fig 15d) shows that reduced stratification in regions around X2 happens concurrently with peak X2 difference, consistent with the theory proposed by Chen and Sanford (2009), who found that the up-estuary wind tends to reduce stratification through wind straining and wind mixing, while down-estuary wind may increase or decrease stratification through competition between wind straining and wind mixing. For regions downstream of Suisun Bay (less than $50 \mathrm{~km}$ away from the Golden Gate bridge), wind-induced stratification change shows fortnightly variability, which is because spring tides can lead to a growth of bottom mixed layer, and therefore reduce wind stress needed to cause decreases in stratification.

The $\mathrm{X} 2$ variation in ConstRiv experiment is within $1 \mathrm{~km}$, smaller than contributions by wind. Therefore, the spring/neap tides in ConstRiv are not important for X2 variability. Comparisons of net salt flux into Suisun Bay between the three process-oriented experiments further show the week spring/neap variability in salt transport close to the delta area (Fig 16a). As discussed above (Figs 9, 15d), for regions downstream of Suisun Bay, spring/neap tides can significantly modify stratification and salt flux, and therefore modulate net salt flux into the subregions of San Pablo Bay, Central Bay and South Bay (Figs 16b, c, d). For San Pablo Bay and Central Bay, the net salt flux in Real2011 is dominated by river flow, evidenced by the difference between NoWind and ConstRiv experiments. Meanwhile, the fluctuation is featured with significant spring/neap variability, consistent with the spring/neap fluctuation in ConstRiv, and modulated by wind with wind effect evidenced by difference between Real2011 and NoWind experiments. For South Bay, where natural discharge input is weak except in spring, the net salt flux is dominated by spring/neap tides, and modulated by winds. 

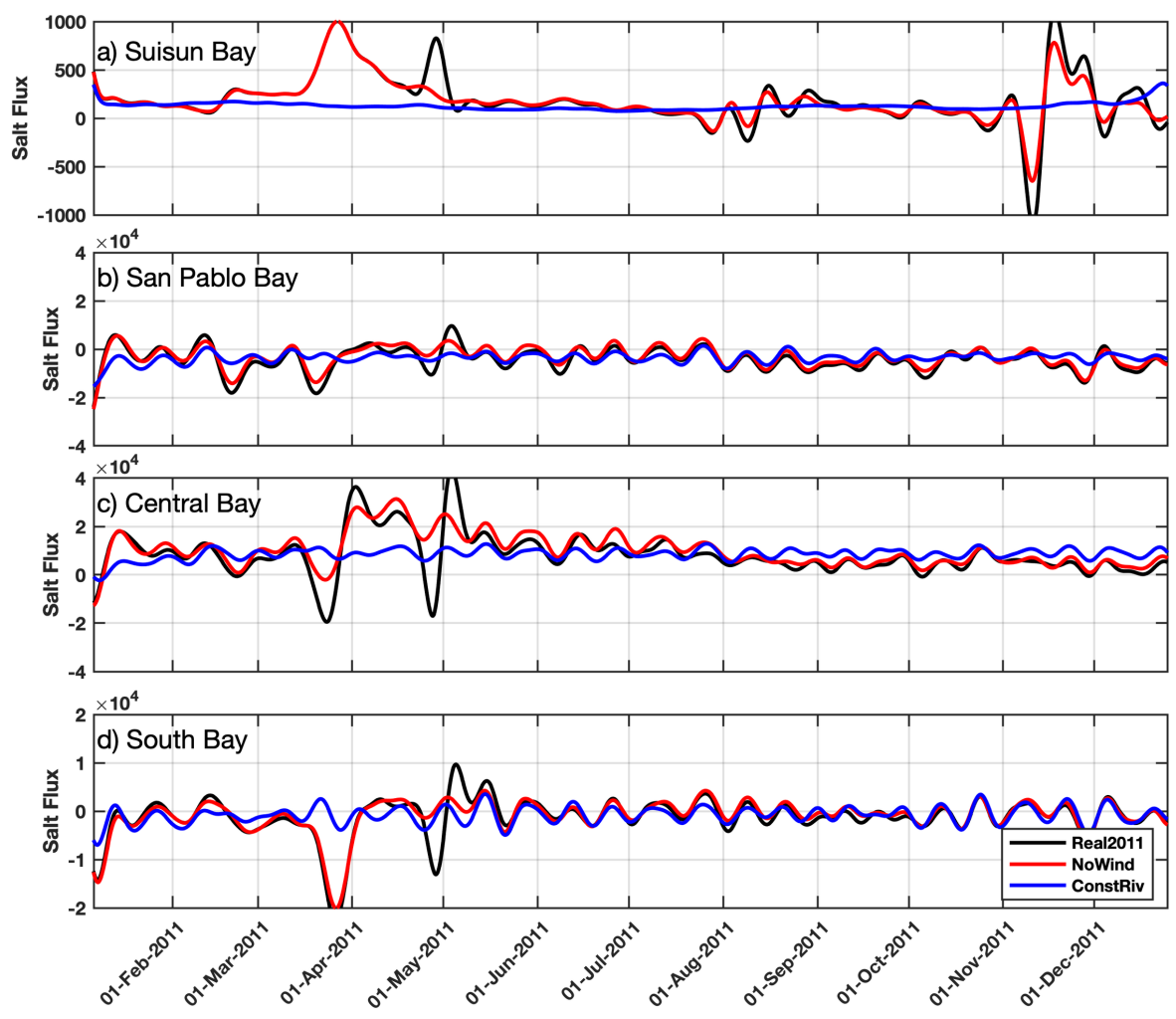

Fig 16. Net salt flux into a) Suisun Bay, b) San Pablo Bay, c) Central Bay and d) South Bay from experiments Real2011, NoWind and ConstRiv experiments. A low pass filter with a cutoff period of 5 day is applied.

\section{Summary}

In this study, we evaluated the Bay version of SFB SCHISM model in simulating the hydrodynamic processes at different time scales, including tidal, spring-neap, and seasonal time scales. The model well produces the time series of surface temperature and water level, tidal currents, tidal ellipses and surface salinity at tidal and subtidal time scales. Even though the model overestimates the strength of $\mathrm{K}_{1}$, considering it well captures the spring-neap variations of tides, evolution of tidal currents, and the dominant tidal currents $\mathrm{M}_{2}$, the model's performance in simulating tides is acceptable. The model also well captures the seasonal variations of surface circulation in Central Bay and the salinity stratification with a good estimate of the seasonal locations of 2-PSU isohaline.

We further explored SFB's hydrodynamic processes at the related timescales through a set of process-oriented experiments. The tidal residual circulation is presented. For South Bay, the tidal residual current features two major circulations in opposite directions: the cyclonic one at the lower South Bay and the anti-cyclonic one located to the north. San Pablo Bay features an anticyclonic gyre. Also, the spring-neap tidal cycle causes fortnightly variations in salinity and 
currents by modulating primarily the vertical mixing and stratification.

Moreover, the seasonal variability of depth-averaged circulation in North Bay is dominated by the change of river discharge and winds, while in South Bay it is dominated by wind with the vertical structures regulated by the density-driven exchange. Wind plays an important role in North Bay and Central Bay by decreasing the vertical stratification through wind straining and mixing, albeit it is usually less important in controlling the vertical structures than rivers. In contrast, in South Bay the wind can change the vertical structures of currents. Particularly, the three-layer flow pattern present in South Bay during September is driven by the wind straining and the sub-surface density-driven exchange.

Net salt flux and contributions from different factors including river flow, wind and spring/neap tides in each subregion are delineated and evidenced through our process-oriented experiments. By investigating X2 through process-oriented experiment, we found that X2 varies by as much as $50 \mathrm{~km}$ and it is proportional to river flow to the $1 / 4$ power, suggesting the primary control of river flow in determining salt intrusion in a mesotidal estuary like the northern SFB. However, X2 can be modified by wind such that X2 is lengthened by 0 to $5 \mathrm{~km}$ during low discharge period. Wind also plays an important role in salt balance for each subregion in SFB. On the other hand, although spring/neap tides have negligible effect on X2, they are important for salt balance downstream of Suisun Bay, and dominate the salt flux in South Bay.

\section{Acknowledgements}

The authors gratefully acknowledge the U.S. Geological Survey (USGS; http://waterdata.usgs.gov/nwis) and the project of Water Quality of San Francisco Bay by USGS (https://sfbay.wr.usgs.gov/access/wqdata) for collecting and sharing the data used in this study. This study was initiated by the funding from NASA through a grant NNX11AP11G (to E.M. Danner at University of California at Santa Cruz) and continuously supported by a NASA Interdisciplinary Science program grant NNX14AD79G (to C.O. Davis at Oregon State University and its subcontractors at San Francisco State University, University of Maine and Remote Sensing Solutions). Computations were carried out using the clusters of the Advanced Computing Group at the University of Maine. 


\section{References}

Abood, K. A., Circulation in the Hudson Estuary, Ann. N.Y. Acad. Sci., 1974 May;250:39-111.

Ateljevich, E., K. Nam, Y. Zhang, R. F. Wang, and Q. Shu. Bay-Delta SELFE calibration overview. Methodology for Flow and Salinity Estimates in the Sacramento-San Joaquin Delta and Suisun Marsh, 35th Annu. Prog.

Rep. Chapter 7, Dep. of Water Resour., Calif. Nat. Resour. Agency, Sacramento, Calif. 2013.

Bennett, W. A., Kimmerer, W. J. \& Burau, J. R. Plasticity in vertical migration by native and exotic estuarine fishes in a dynamic low-salinity zone. Limnol. Oceanogr., 2002 Sep 6;47:1496-1507.

Bowen, M. M., Mechanisms and variability of salt transport in partially-stratified estuaries, report, 198 pp., Joint Program in Phys. Oceanogr., Woods Hole, Mass; 2000 Feb.

Chao, Y., J. D. Farrara, H. Zhang, K. J. Armenta, L. Centurioni, F. Chavez, J. B. Girton, D. Rudnick, R. K. Walter. Development, implementation and validation of a California coastal ocean modeling, data assimilation and forecasting system. Deep Sea Res. II. 2018 May;151:49-63.

Chao, Y., J. D. Farrara, H. Zhang, Y. J. Zhang, E. Ateljevich, F. Chai, C. O. Davis, R. Dugdale, F. Wilkerson. Development, implementation, and validation of a modeling system for the San Francisco Bay and Estuary. Estuar., Coast. Shelf Sci. 2017 Jul 15;194:40-56.

Chen, S.-N., and L. P. Sanford: Axial wind effects on stratification and longitudinal salt transport in an idealized, partially mixed estuary. J. Phys. Oceanogr. 2009 Aug 1;39:1905-1920.

Chua, V.P., Fringer, O.B. Sensitivity analysis of three-dimensional salinity simulations in North San Francisco Bay using the unstructured-grid SUNTANS model. Ocean. Model. 2011; 39(3):332-350.

Cloern, J. E. Tidal stirring and phytoplankton bloom dynamics in an estuary, J. Mar. Res. 1991 Feb 1;49:203-221.

Conomos, T. J., Smith, R. E., \& Gartner, J. W. Environmental setting of San Francisco Bay. Hydrobiologia. 1985 Oct;129(1):1-12. https://doi.org/10.1007/BF00048684.

Coogan, J. and Dzwonkowski, B. Observations of Wind Forcing Effects on Estuary Length and Salinity Flux in a River-Dominated, Microtidal Estuary, Mobile Bay, Alabama. J. Phys. Oceanogr. 2018 Aug 1;8(48):17871802.

Doyle, J.D., Jiang, Q., Chao, Y., Farrara, J. High-resolution atmospheric modeling over the Monterey Bay during AOSN II. Deep Sea Res. II. 2009 Feb;56:87-99.

Dugdale, R., Wilkerson, F., Parker, A. E., Marchi, A., \& Taberski, K. River flow and ammonium discharge determine spring phytoplankton blooms in an urbanized estuary. Estuar., Coast. Shelf Sci. 2012 Dec;115:187199. https://doi.org/10.1016/j.ecss.2012.08.025.

Ford, M., Wang, J., \& Cheng T. Predicting the vertical structure of tidal current and salinity in San Francisco Bay, California. Water Resour. Res. 1990 May;26(5):1027-1045.

Geyer, W. R. The importance of suppression of turbulence by stratification on the estuarine turbidity maximum. Estuaries. 1993 Mar;16(1):113-125. https://doi.org/10.2307/1352769.

Gross, E.S., Koseff, J.R., Monismith, S.G. Three-dimensional salinity simulations of South San Francisco Bay. J. Hydraul. Eng. 1999 Nov 1;125(11):1199-1209.

Gross, E.S., MacWilliams, M.L., Kimmerer, W. Simulating periodic stratification in the San Francisco estuary. In: Proceedings of the 9th International Conference on Estuarine and Coastal Modeling, ASCE Conference Proceedings. 2005; 155-175.

Gross, E.S., MacWilliams, M.L. Three-dimensional modeling of tidal hydrodynamics in the San Francisco estuary San Franc. Estuary Watershed Sci. [Internet]. 2009;7(2)

Hansen, D. V., and M. Rattray. Gravitational circulation in straits and estuaries, J. Mar. Res. 1965; 23:104-122.

Holleman, R.C., Stacey, M.T. Coupling of sea level rise, tidal amplification, and inundation. J. Phys. Oceanogr. 2014 May 1; 44(5):1439-1455.

Hunkins, K. Salt dispersion in the Hudson Estuary, J. Phys. Oceanogr. 1981 May 1; 11(5):729-738.

Jassby, A. D., W.J. Kimmerer, S.G. Monismith, C. Armor, J.E. Cloern, T.M. Powell, J.R. Schubel, T.J. Vendlinski Isohaline position as a habitat indicator for estuarine populations. Ecol. Appl. 1995;5(1):272-289. 
Kimmerer, W. J. Effects of freshwater flow on abundance of estuarine organisms: Physical effects or trophic linkages. Mar. Ecol. Prog. Ser. 2002;243:39-55.

Liu, Y., MacCready, P., Hickey, B. M., Dever, E. P., Kosro, P. M., \& Banas, N. S. Evaluation of a coastal ocean circulation model for the Columbia River plume in summer 2004. J. Geophys. Res.: Oceans. 2009 Mar 10; 114(C2), 192:C00B04.

Liu, Q., Chai, F., Dugdale, R., Chao, Y., Xue, H., Rao, S., Wilkerson, F., Farrara, J., Zhang, H., Wang, Z., \& Zhang, Y. San Francisco Bay nutrients and plankton dynamics as simulated by a coupled hydrodynamic-ecosystem model. Cont. Shelf Res. 2018 Mar;161:29-48.

Liu, Q., Rothstein, L. M., Luo, Y., Ullam, D.S., \& Codiga, D. L. Dynamics of the periphery current in Rhode Island Sound. Ocean Model., 2016 Sep;105:13-24.

Loder, J.W. Topographic rectification of tidal currents on the sides of Georges Bank. J. Phys. Oceanogr. 1980 Sep 1;10 (9):1399-1416.

MacWilliams, M.L., F.G. Salcedo, and E.S. Gross. San Francisco Bay-Delta UnTRIM Model Calibration Report, POD 3-D Particle Tracking Modeling Study, Prepared for California Department of Water Resources. 2008 Dec 19;344.

MacWilliams, M.L., Bever, A.J., Gross, E.S., Ketefian, G.S. \& Kimmerer, W.J. Three-dimensional modeling of hydrodynamics and salinity in the San Francisco Estuary: An evaluation of model accuracy, X2, and the lowsalinity Zone. San Francisco Estuary and Watershed Science, 2015 Apr;13(1).

Martyr-Koller, R.C., Kernkamp, H.W.J., van Dam, A., van der Wegen, M., Lucas, L.V., Knowles, N., Jaffe, B., Fregoso, T.A. Application of an unstructured 3D finite volume numerical model to flows and salinity dynamics in the San Francisco Bay-Delta. Estuar., Coast. Shelf Sci. 2017 Jun 5;192:86-107.

Monismith, S. G., \& Fong, D. A. A simple model of mixing in stratified tidal flows. J. Geophys. Res.: Oceans. 1996 Dec 15;101(C12), 28583-28595.

Monismith, S., J. R. Burau, and M. Stacey. Structure and Flow-Induced Variability of the Subtidal Salinity Field in Northern San Francisco Bay, J. Phys. Oceanogr. 2002 Nov 1;32(11):3003-3019.

Moyes C. D. and Schulte, P. M. Principles of Animal Physiology. $2^{\text {nd }}$ ed. Pearson; 2008.

Nidzieko, N. J., Hench, J. L., and Monismith, S. G. Lateral circulation in well-mixed and stratified estuarine flows with curvature. J. Phys. Oceanogr., 2009 Apr 1;39(4), 831-851.

Novick E, Senn D. External nutrient loads to San Francisco Bay. San Francisco Estuary Institute. Richmond, CA. Contribution (704); 2014.

Peng, M., Jr., R. A. S., Zhang, A., \& Iii, F. A. Towards the Development of the National Ocean Service San Francisco Bay Operational Forecast System. Journal of Marine Science and Engineering. 2014 Mar 24;2(1): 247-286.

Peters, H. Observations of Stratified Turbulent Mixing in an Estuary: Neap-to-spring Variations During High River Flow. Estuar., Coast. Shelf Sci.1997 Jul;45(1):69-88.

Pritchard, D. W. A study of the salt balance in a coastal plain estuary, J. Mar. Res., 1954;13:133-144.

Scully, M. E., C. T. Friedrichs, and J. M. Brubaker. Control of estuarine stratification and mixing by wind-induced straining of the estuarine density field. Estuaries. 2005 Jun;28:321-326.

Shaha, D. C., Cho, Y.-K., Seo, G.-H., Kim, C.-S., \& Jung, K. T. Using flushing rate to investigate spring-neap and spatial variations of gravitational circulation and tidal exchanges in an estuary. Hydrol. Earth Syst. Sci., 2010 Aug 5;14(8):1465-1476.

Sharples, J. Potential impacts of the spring-neap tidal cycle on shelf sea primary production. J. Plankton Res. 2008 Feb; 30(2):183-197.

Sharples, J., B. E. Scott, and M. E. Inall. From physics to fishing over a shelf sea bank, Prog. Oceanogr. 2013 Oct;117:1-8.

Shellenbarger, G. G., Wright, S.A., Schoellhamer, D.H. A sediment budget for the southern reach in San Francisco Bay, CA: implications for habitat restoration. Marine Geology,2013;345:281-293. 
Shi, F., Hanes, D.M., Kirby, J.T., Erikson, L., Barnard, P.L., and Eshleman, J. Pressure gradient-dominated nearshore circulation on a beach influenced by a large inlet-tidal shoal system. J. Geophy. Res.: Oceans, 2011 Apr 21;116:C04020.

Simpson, J. H., \& Souza, A. J. Semidiurnal switching of stratification in the region of freshwater influence of the Rhine. J. Geophy. Res.: Oceans, 1995 Apr 15;100(C4):7037-7044.

Smith, L. H. A review of circulation and mixing studies of San Francisco Bay, California (USGS Numbered Series No. 1015). U.S. G.P.O; 1987.

Uncles, R. J., \& Stephens, J. A. Salt Intrusion in the Tweed Estuary. Estuar., Coast. Shelf Sci., 1996 Sep;43(3):271293.

Walters, R. A., Cheng, R. T., \& Conomos, T. J. Time scales of circulation and mixing processes of San Francisco Bay waters. Hydrobiologia. 1985;129(1):13-36.

Wang, J. A two-channel laterally averaged estuarine circulation model (LAECIM), J. Geophy. Res.: Oceans. 1998; 103(C9):18381-18391.

Wells, A. W., and J. R. Young. Long-term variability and predictability of Hudson River physical and chemical characteristics. In: Smith CL, editor. Estuarine Research in the 1980's. State University of New York Press, Albany. 1992;29-58.

Willmott, C. J. On the validation of models. Physical Geography. 1981;2(2):184-194.

Zhang, Y., and Baptista, A.M. SELFE: A semi-implicit Eulerian-Lagrangian finite-element model for cross-scale ocean circulation. Ocean Model. 2008;21(3-4):71-96.

Zhang, Y. J., Witter, R. C., \& Priest, G. R. Tsunami-tide interaction in 1964 Prince William Sound tsunami. Ocean Model., 2011;40(3-4):246-259.

Zhang, Y., E. Ateljevich, H-C. Yu, C-H. Wu, and J.C.S. Yu. A new vertical coordinate system for a threedimensional unstructured-grid model, Ocean Model. 2015 Jan;85:16-31.

Zhang, Y., Ye, F., Stanev, E.V. and Grashorn, S. Seamless cross-scale modeling with SCHISM, Ocean Model., 2016 Jun;102:64-81.

\section{Supporting information}

S1 Fig shows the temporal variations of modeled surface and bottom salinity in comparison with the observed salinity throughout the water column at single USGS station (Fig 1b). The red and blue lines represent the hourly surface and bottom salinity in 2011 from the experiment Real2011, and green dots show observed salinity spanning the water column during near monthly USGS samplings, representing the range of salinity. Consistent with observations, the model results show USGS 657 and 2, which are immediately downstream of the Delta, with weak stratification and salinity close to 0 throughout the year. Moving toward Central Bay, the stratification increases gradually with peak values around USGS 16 and 17; moving toward South Bay from Central Bay, the stratification becomes weaker with the salinity generally higher than North Bay. The model results fit nicely with the observations over most of the studied region with strong seasonal variability in salinity stratification. However, at the end of March, when river discharge peaks, the model underestimates the bottom salinity from USGS stations 12 to 29 (from San Pablo Bay to upper South Bay, also seen in the third panel from the top on the right in Fig 5). This implies that the model underestimates the bottom salt-water intrusion from the coastal ocean during the peak discharge.

The observed surface and bottom salinity at the USGS Richmond station from May to July 2011 (S2a Fig) shows that the salinity fluctuates with tidal periods. Spectral analysis of the salinity 
stratification (S2b Fig) finds the strong signals at semi-diurnal tidal (M2) period (0.5175 day), diurnal period, and fortnightly period. The fortnightly period signal is caused by the tidal springneap variations.
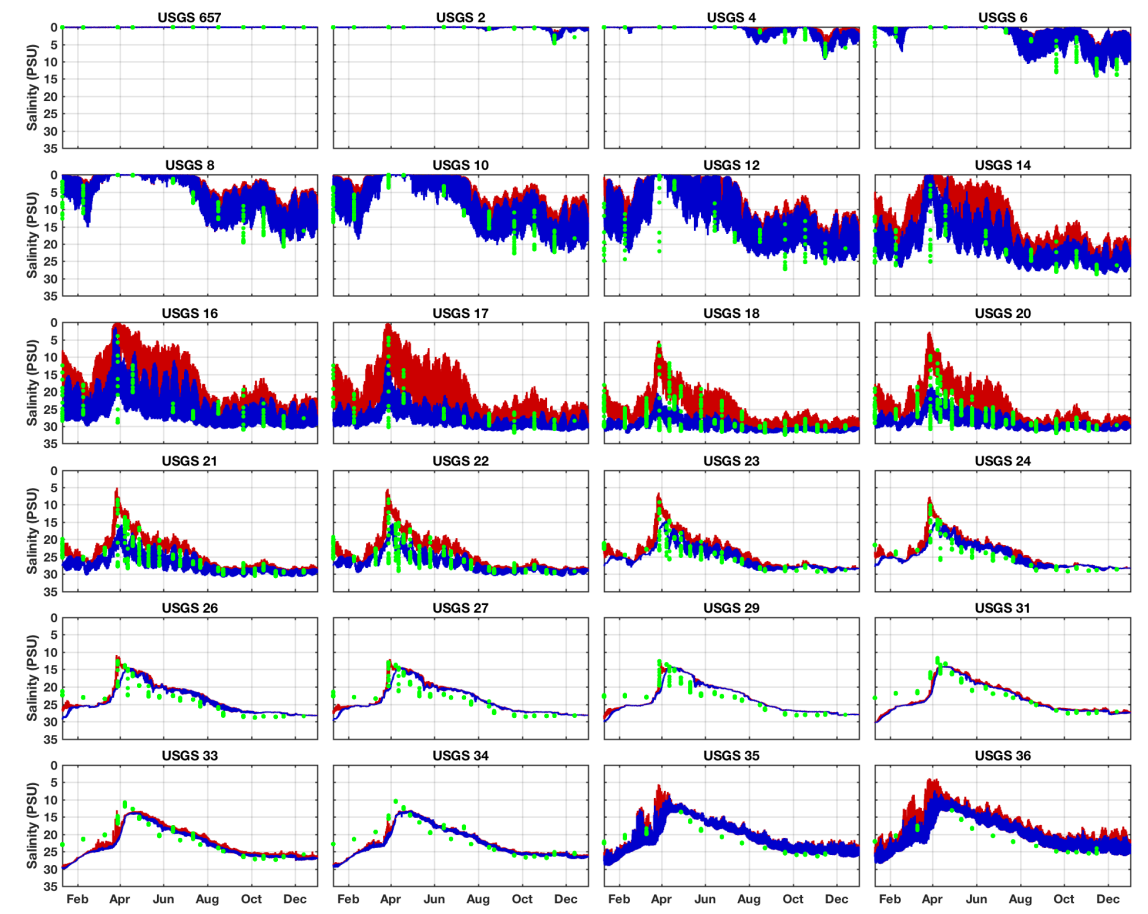

Figure S1. Comparisons of observed and modeled salinity at the USGS stations throughout SFB (marked as magenta dots in Fig 1b). The red lines represent modeled surface salinity and blue lines for modeled bottom salinity. The green dots represent observed salinity at depths spanning the water column.
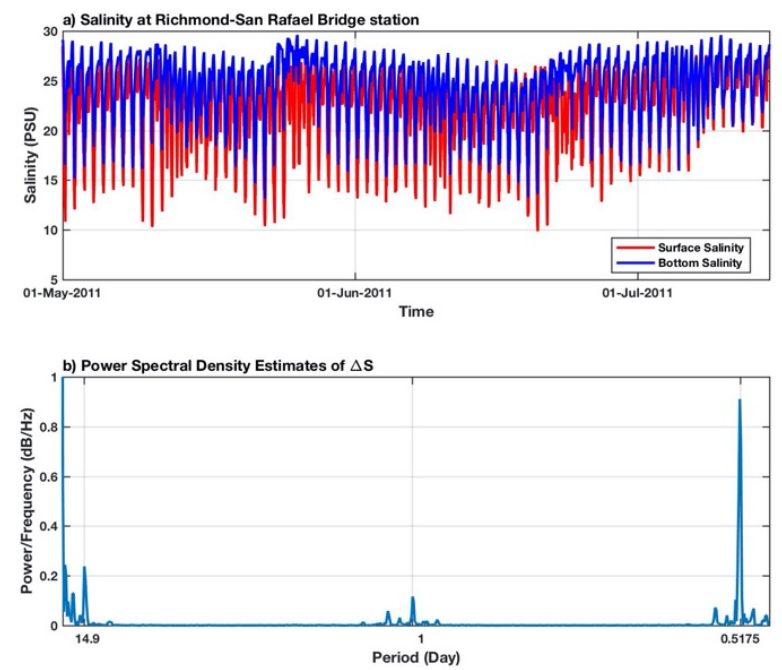

Figure S2. Salinity at the Richmond-San Rafael Bridge station with a) showing the surface and bottom salinity in every 15 minutes, and b) showing the power spectral density estimates of salinity stratification $\Delta \mathrm{S}$. The salinity is obtained from https://ca.water.usgs.gov/projects/baydelta/. 
Without the signals from seasonal river discharge, this experiment ConstRiv clearly shows the estuarine circulation and tidal asymmetry (Simpson and Souza, 1995). Figs S3a and S3c show the time series of vertical structure of velocity and salinity at a point in Golden Gate during one day for the experiment ConstRiv with the tidal averaged flow and salinity shown in Figs S3b and S3d. During ebb (from hours 6 to 10), surface intensified currents move from SFB to the coastal ocean, entraining freshwater in upper layers over saltier water in deeper layers. Around hour 10, bottom velocities reverse, while currents at top layers remain seaward due to the riverine flow. During this time, the maximum salinity stratification occurs with the peak amount of freshwater from SFB. During flood (from hours 12 to 16), currents over the whole water column move toward SFB, with a maximum velocity of $1.4 \mathrm{~m} / \mathrm{s}$ reached around $30 \mathrm{~m}$ from the surface.

S4 Fig shows monthly mean depth-averaged circulation difference between experiments Real2011 and NoWind (Real2011-NoWind). It shows that the existence of winds in Real2011 experiment is corresponding to a stronger cyclonic circulation in San Pablo Bay from March to September, while a weaker cyclonic circulation in December. For South Bay, the change of circulation pattern under winds' influence is more complicated.
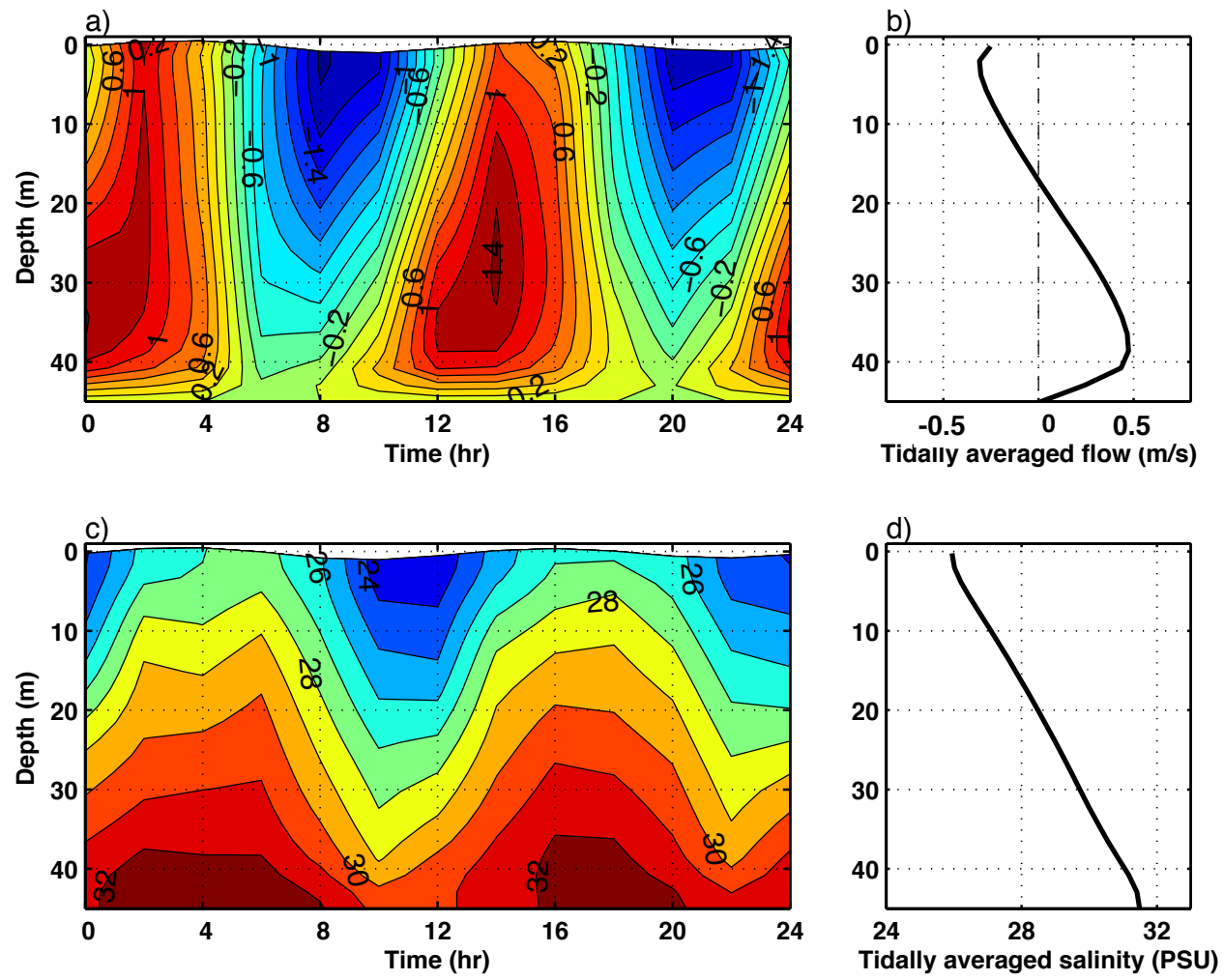

Figure S3. Time series of vertical profile of a) currents (in $\mathrm{cm} / \mathrm{s}$ ) along the Golden Gate strait at a station in the middle of the Golden Gate strait and c) salinity (in PSU) at the same station for the experiment 
ConstRiv. Positive velocities represent bay-ward current, and negative for seaward current. b) Tidally averaged flow and d) tidally averaged salinity.
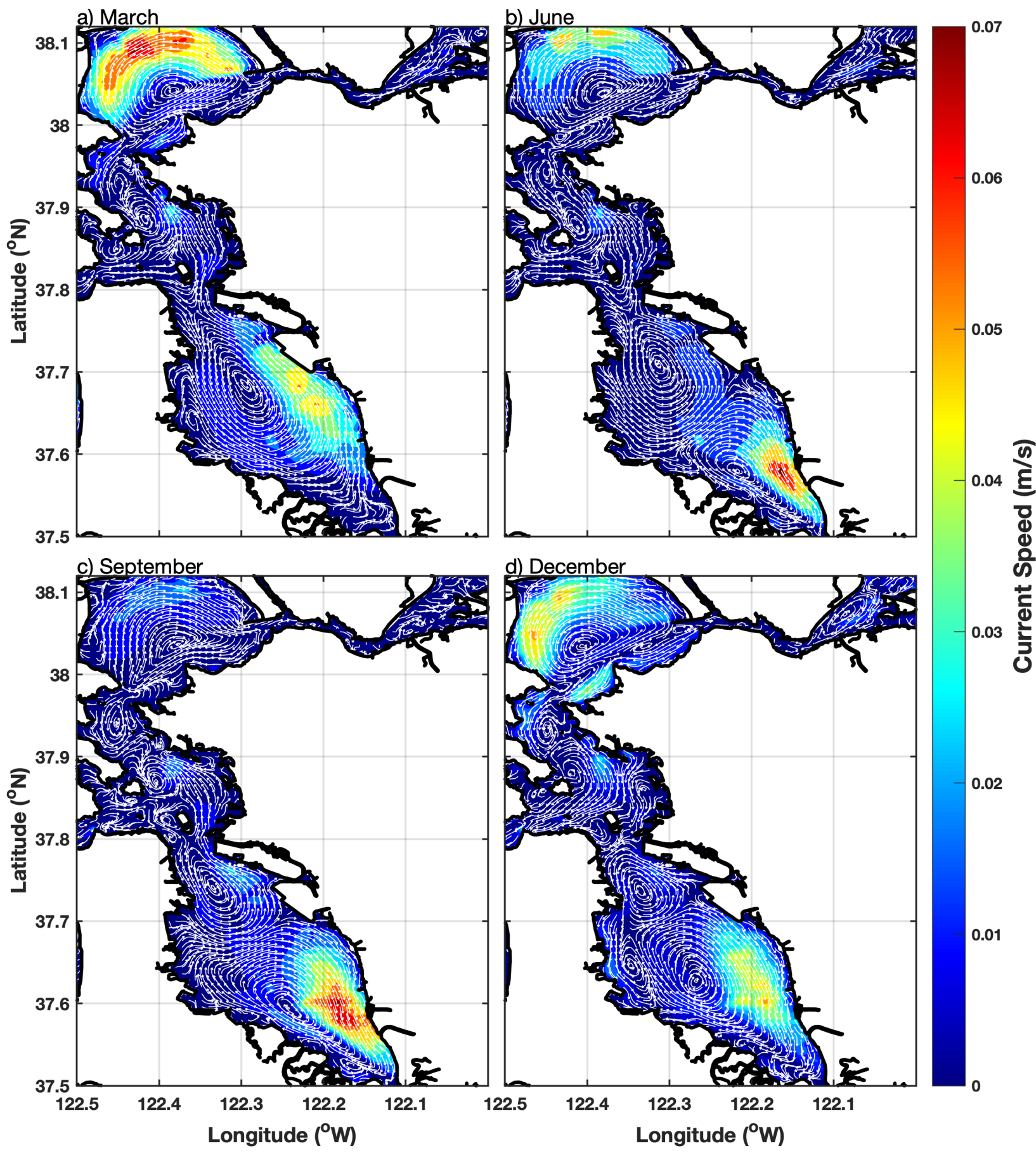

Figure S4. Monthly mean depth-averaged circulation difference between experiments Real2011 and NoWind (Real2011-NoWind) in SFB in a) March, b) June, c) September and d) December. 